\title{
The Effect of the N-Terminus on Heme Cavity Structure, Ligand Equilibrium and Rate Constants and Reduction Potentials of Nitrophorin 2 from Rhodnius prolixust
}

\author{
Robert E. Berry, Tatiana Kh. Shokhireva, Igor Filippov, Maxim N. Shokhirev, Hongjun \\ Zhang, and F. Ann Walker \\ Department of Chemistry, The University of Arizona, PO Box 210041, Tucson, Arizona 85721-0041
}

\begin{abstract}
The D1A mutant of recombinant NP2 has been prepared and shown to have the expression-initiation methionine-0 cleaved during expression in E. coli, as is the case for recombinant NP4, where Ala is the first amino acid for the recombinant protein, as well as for the mature native protein. The heme substituent ${ }^{1} \mathrm{H}$ NMR chemical shifts of NP2-D1A and those of its imidazole, $\mathrm{N}$-methylimidazole and cyanide complexes are rather different from those of NP2-M0D1. This difference is likely due to the much smaller size of the N-terminal amino acid (A) of NP2-D1A, which allows formation of the closed loop form of this protein, as it does for NP4 (Weichsel, A.; Andersen, J. F.; Roberts, S. A.; Montfort, W. R Nature Struct. Biol. 2000, 7, 551-554). The ratio of the two hemin rotational isomers $\mathbf{A}$ and $\mathbf{B}$ is different for the two proteins, and the rate at which the $\mathbf{A}: \mathbf{B}$ ratio reaches equilibrium is strikingly different (NP2-M0D1 $t_{1 / 2}$ for heme rotation $\sim 2 \mathrm{~h}, \mathrm{NP} 2-\mathrm{D} 1 \mathrm{~A} \mathrm{t}_{1 / 2} \sim 43 \mathrm{~h}$ ). This difference is consistent with a high stability of the closed loop form of the NP2-D1A protein, and infrequent opening of the loops that could allow heme to at least partially exit the binding pocket in order to rotate about its $\alpha, \gamma$-meso axis. Consistent with this, the rates of histamine binding and release to/from NP2-D1A are significantly slower than for NP2-M0D1 at $\mathrm{pH} 7.5$. This work suggests that care must be taken in interpreting data obtained from proteins that carry the expression-initiation M0.
\end{abstract}

The nitrophorins (nitro $=\mathrm{NO}$, phorin $=$ carrier ) are a group of NO-carrying heme proteins found in the saliva of at least two species of blood-sucking insects, Rhodnius prolixus, the "kissing bug", which has four such proteins in the adult insect $(1-5)$ and at least three additional nitrophorins in earlier stages of development $\left(6^{7}, 7\right)$, and Cimex lectularius, the bedbug, which has only one nitrophorin protein $\left({ }_{8}, 9\right)$. These interesting heme proteins sequester nitric oxide that is produced by a nitric oxide synthase (NOS) present in the cells of the salivary glands that is similar to vertebrate constituitive NOS $\left(10^{-12}\right)$. NO is kept stable for long periods of time by binding it as an axial ligand to a ferriheme Fe center $(1,3-5)$. Upon injection into the tissues of the victim, NO dissociates, diffuses through the tissues to the nearby capillaries to cause vasodilation and thereby allows more blood to be transported to the site of the wound. At the same time, histamine, whose role is to cause swelling, itching, and initiating the immune response, is released by mast cells and platelets of the victim. In the case of the Rhodnius proteins, this histamine binds to the heme Fe sites of the nitrophorins, hence preventing the insect's detection for a period of time, which allows it to obtain a sufficient blood meal (13).

\footnotetext{
${ }^{\dagger}$ This work was supported by National Institutes of Health grant HL54826.

Address correspondence to: F. Ann Walker, Department of Chemistry, The University of Arizona, Tucson, Arizona 85721-0041, Tel. + +520 621-8645; Fax. ++520 626-9300; E-Mail: awalker@u.arizona.edu.
} 
The Rhodnius proteins of the adult insect, which have been named NP1-4 in order of their abundances in the insect saliva, have been investigated by a number of techniques $(1,3,14$ 30 ), including spectroelectrochemistry (14,16-18), infrared (14) and resonance Raman (15), NMR (14, 17, $19-21)$, EPR $(1,14,22)$ and Mössbauer (23)spectroscopies, stopped-flow photometry $(16,24)$, and the solid state structures of more than one ligand complex of NP1 $(14,25)$, NP2 ( ${ }^{26}$, Weichsel, A.; Berry, R. E.; Zhang, H.; Walker, F. A.; Montfort, W. R., to be submitted), and NP4 $\left(27^{-32}\right)$ have been determined by X-ray crystallography. The structures are unique for heme proteins, in that the heme is located at the open end of an 8 -stranded $\beta$ barrel of the lipocalin fold $(8,33)$, rather than in the more commonly-observed largely $\alpha$-helical globin $\left(34^{-38}\right)$ or 4 -helix bundle $(39-42)$ folds. The ferriheme molecule is bound to the protein via a histidine ligand, and the sixth coordination site is available to bind NO or other ligands. In the NO-off form in vitro, either water or ammonia, depending on buffer type, is bound to the sixth site $(25,27)$.

In vivo, the gene for each of the nitrophorins encodes the protein including a presequence that targets it for export, which is cleaved as the protein matures in the cells of the salivary glands of the insect (Scheme 1). For NP4 the first amino acid of the mature protein is alanine, while for NP1 it is lysine, and for NP2 and NP3 it is aspartic acid (Scheme 1) $\left(3^{-5}\right)$. Since the report of the first structure of recombinant NP4-NO (27) it has been known that binding of NO to this protein induces closure of the entrance to the distal heme pocket, where hydrogen-bonds are formed between the side chains of the A-B and G-H loops, as shown in Figure 1. The N-terminal amino group of Ala-1 also participates in the hydrogen-bonding network that creates the closed loop conformation of NP4-NO $\left(27^{-30}\right)$. However, NP4 is the only recombinant nitrophorin for which the start-codon methionine of the truncated gene that encodes the mature form of the protein is cleaved as the protein matures in E. coli $\left(27^{-29}\right)$. Therefore, we wondered what the effect of the Met-0 of recombinant NP2, hereafter denoted NP2-M0D1, might be on the ability of the A-B and G-H loops to close upon binding of nitric oxide and other ligands. We thus prepared the D1A mutant of NP2. As reported earlier for NP4 $\left(27^{-29}\right)$, we found that the Met-0 was processed off when the gene for NP2-D1A was expressed in E. coli. As presented in this work, we have characterized NP2-D1A and its ligand complexes by optical and NMR spectroscopy, mass spectrometery and by spectroelectrochemistry, measurement of ligand binding constants and measurement of the kinetics of heme rotation and of histamine binding and release. We find that although the reduction potentials of the mutant protein in the absence and presence of axial ligands are very similar to those of the wild-type protein having the Met-0 present, the NMR spectra of the ferriheme mutant protein in the absence and presence of axial ligands are rather different, as are the equilibrium ratios of the two heme orientation isomers $\mathbf{A}$ and $\mathbf{B}$ and the rates of their interconversion are very different. The rate of histamine release from NP2-M0D1 and NP2-D1A are also very different. The similarities and differences between the recombinant protein NP2-M0D1 and its mutants NP2-D1A and NP2-GSHM0D1 (prepared for a different purpose and used in this study as a possible partial model of the uncleaved MELYTALLAVTILCLTSTMGVSG leader sequence of the immature protein), Scheme 1 (note that the NP2 sequences discussed in this work are boxed), and the implications for the behavior of native unprocessed and processed NP2 proteins are discussed. It is found that heme orientation kinetics and thermodynamics, measured by NMR spectroscopy, are useful monitors of protein conformational dynamics of the nitrophorins.

\section{Experimental Section}

\section{Protein Preparation and Characterization of the Recombinant Proteins}

Cloning and expression plasmids used were those reported previously $(17,26)$. The Asp $\rightarrow$ Ala site-directed mutant gene was prepared according to standard genetic engineering methods using the gene encoding the wild type NP2 sequence beginning with Asp-1, cloned into the pET24a expression vector (Novagen). The NP2-GSHM0D1 construct was prepared using the 
gene encoding the wild type NP2 sequence cloned into the pET28a expression vector (Novagen) immediately downstream of the $\mathrm{His}_{6}$-tag containing the thrombin proteolytic cleavage site. The recombinant proteins NP2-M0D1 and NP2-D1A were expressed and purified as described previously $(14,24-26)$ with the following alterations. All Tris-based buffers where substituted with $100 \mathrm{mM}$ sodium phosphate buffers at $\mathrm{pH} 7.5$ to eliminate trace ligands found to be present when using Tris buffers. The isolated apo-protein was first purified by size exclusion chromatography (using a HighPrepi ${ }^{\mathrm{TM}} 26 / 60$ Sephacryl S-100 column at $\mathrm{pH}$ $7.5100 \mathrm{mM}$ sodium phosphate buffer with $100 \mathrm{mM} \mathrm{NaCl}$ ) before titration with heme (dissolved in dimethylsulfoxide) and further purified by size exclusion chromatography (at pH 5.0100 $\mathrm{mM}$ sodium acetate buffer with $100 \mathrm{mM} \mathrm{NaCl}$ ). NP2-M0D1 and NP2-D1A were stored in lyophilized form at $-80^{\circ} \mathrm{C}$ until use. The mutant protein was preliminarily characterized by mass spectrometry (MALDI-TOF).

The recombinant protein NP2-GSHM0D1, which was prepared by a method designed for efficient isotopic labeling of the protein for use in 3D structure determination by NMR spectroscopy, to be discussed elsewhere (Filippov, I.; Walker, F. A., to be submitted), was expressed as inclusion bodies and renatured by an oxidative refolding method (43). Purification of the apoprotein employed its $\mathrm{His}_{6}$-tag that was subsequently removed by thrombin proteolytic cleavage to leave the uncleaved non-native N-terminus residues GSHM; because of the disulfide bond involving Cys-2, shorter non-native fragments did not permit thrombin proteolytic cleavage of the $\mathrm{His}_{6}$ tag. Hemin was then titrated into this apoprotein and the holoprotein was purified as described above.

\section{NMR sample preparation}

NMR samples were prepared as $1-4 \mathrm{mM}$ solutions of the protein in $\mathrm{D}_{2} \mathrm{O}$ containing $30 \mathrm{mM}$ phosphate buffer at $\mathrm{pH} 7.0$ (uncorrected for the deuterium isotope effect). To obtain the lowspin complexes, the high-spin NP protein was titrated with the desired ligand (cyanide, Nmethylimidazole (NMeIm), or imidazole ( $\operatorname{ImH})$ ) until the proton NMR signals in the 70-30 ppm region had just disappeared. Concomitantly, these signals were replaced by much sharper signals in the 30-10 ppm region. Especially for the cyanide complex, it has been found to be extremely important not to add any more ligand than necessary to cause disappearance of the high-spin resonances, and in fact, less than a stoichiometric amount of cyanide was found to be necessary for EPR measurements to avoid formation of some of the bis-cyanide complex, which had lost its protein-provided histidine ligand (21). At ambient temperatures, NMR samples of the cyanide complex were prepared by adding no more than one equivalent of potassium cyanide to NP2-D1A at pH 7.0. The binding constant of cyanide to NP2 and its mutants studied herein is too large to measure, meaning that $K_{d} \ll<1 \mathrm{nM}$, and thus the concentration of $\mathrm{OH}^{-}$and $\mathrm{HCN}$ produced by hydrolysis of $\mathrm{KCN}$ at $\mathrm{pH} 7.0<<1 \mathrm{nM}$; thus 30 $\mathrm{mM}$ phosphate buffer at $\mathrm{pH} 7.0$ is more than sufficient to maintain the $\mathrm{pH}$ of the NMR sample of the cyanide complex.

\section{NMR data collection}

NMR spectra were collected over the temperature range 25 to $37^{\circ} \mathrm{C}$ with the proton chemical shifts referenced to residual water. WEFT-NOESY and HMQC spectra were obtained on a Bruker DRX-500 spectrometer operating at $500.03 \mathrm{MHz}$ proton Larmor frequency and a Bruker DRX-600 spectrometer operating at $600.13 \mathrm{MHz}$. The ${ }^{1} \mathrm{H}-{ }^{13} \mathrm{C}$ HMQC experiments were recorded using a $5 \mathrm{~mm}$ inverse-detection probe with decoupling during acquisition. A recycle time of $200 \mathrm{~ms}$ and refocusing time of $2.5 \mathrm{~ms}(\mathrm{~J}=200)$ were used. The WEFT-NOESY experiments utilized a $140 \mathrm{~ms}$ relaxation delay and $130-150 \mathrm{~ms}$ recovery-delay. The mixing time for the NOESY experiments was 12-32 ms. All 2D spectra were collected with 1024 or 2048 data points in $t_{2}$ and with $256-512$ blocks in $t_{1}$ with $400-512$ scans/block. 
Investigation of the $\mathbf{A} / \mathbf{B}$ heme equilibration of NP2-D1A, NP2-M0D1 and NP2-GSHM0D1. The NP2-D1A mutant and NP2-M0D1 proteins, prepared with standard procedures described above and lyophilized and stored at $-20{ }^{\circ} \mathrm{C}$, were used for this investigation. The $\mathbf{A}: \mathbf{B}$ ratio was measured from 1D NMR spectra by integrating resonances of each heme orientation that did not overlap with other resonances. For NP2-M0D1 and NP2-GSHM0D1 the A:B heme ratio reached equilibrium within about six hours following heme addition, while for NP2-D1A approach to the A:B equilibrium ratio was very slow. The first spectrum of NP2-D1A was obtained after the sample had been equilibrated at room temperature for 30 minutes. Half of this sample was used to prepare three low-spin complexes having $\mathrm{CN}^{-}$, ImH or NMeIm added (denoted \#1), and the NMR spectra of these fresh samples were recorded. The other half of the high-spin sample and the newly-prepared low-spin complexes \#1 were kept at room temperature for four days and then the NMR spectra were recorded again (denoted \#2). After recording the high-spin spectrum (\#2), this sample was split into three parts and the same axial ligands were added to this partially-equilibrated sample of the high-spin complex. NMR spectra of the resulting low-spin complexes (now denoted \#2) were recorded immediately. The A:B ratios were checked in these low-spin \#2 and \#1 complexes after another three, and then an additional four days (11 in all).

\section{Spectroelectrochemistry}

Methods used for spectroelectrochemical measurements have been described elsewhere (14, $16-18$ ). Reduction potentials of NP2-MOD1 and its NO, imidazole and histamine complexes have been reported at $\mathrm{pH} 5.5$ and 7.5 (16). For the NP2-D1A mutant, protein solutions ( 100 $\mu \mathrm{M})$ for electrochemical studies were prepared as described previously $(14,16-18)$ in 100 $\mathrm{mM}$ phosphate buffer at $\mathrm{pH} 5.5$ and 7.5 by using $1 \mathrm{mM}$ methyl viologen (Aldrich) and $0.2 \mathrm{mM}$ $\mathrm{Ru}\left(\mathrm{NH}_{3}\right)_{6} \mathrm{Cl}_{3}$ (Aldrich) as electrochemical mediators, except for the measurements in the presence of imidazole (Aldrich) and histamine (Aldrich), which required the more negative potential electrochemical mediator, 1-methyl-4,4'-bipyridium (prepared as described by Yamaguchi et al. (44)) to be used instead of the dimethyl analog typically called methyl viologen. Electrochemical titrations were carried out using the same instrumentation and the same type of $\mathrm{Ag} / \mathrm{AgCl}$ reference electrode ( $-205 \mathrm{mV} v s$. SHE), as described previously (14, $16-18$. In a series of steps the potential was set at a chosen value $E_{a p p}$ for a period of 5-10 min until the optical spectrum did not change further with time. The optical spectrum was then recorded and saved, a new potential $\mathrm{E}_{\mathrm{app}}$ was set and the process was repeated, etc. The temperature of the measurements was $27 \pm 1^{\circ} \mathrm{C}$. The data were analyzed in terms of the Nernst equation, which describes the effect of applied potential on the ratio of the concentrations of oxidized and reduced forms of the complex and the standard reduction potential, $\mathrm{E}^{\mathrm{o}}$ :

$$
\mathrm{E}_{\mathrm{app}}=\mathrm{E}^{\mathrm{O}}+2.303(\mathrm{RT} / \mathrm{nF}) \log _{10}([\mathrm{Ox}] /[\text { Red }])
$$

where $\mathrm{E}_{\mathrm{app}}$ is the applied potential, $\mathrm{E}^{\mathrm{o}}$ is the reduction potential determined from these data, and [Ox] and [Red] are the equilibrium concentrations of the protein in the $\mathrm{Fe}(\mathrm{III})$ and $\mathrm{Fe}$ (II) states, respectively, in the presence of either no ligand or a high enough concentration of ligand $\mathrm{L}$ to insure full complexation of both oxidation states. [Ox] and [Red] are calculated from the optical spectra using Beer's law, and fit to the Nernst equation using the nonliner-least-squares fitting algorithm in the software Origin $\odot$.

The shift of the $\mathrm{Fe}^{\mathrm{III}} / \mathrm{Fe}^{\mathrm{II}}$ reduction potential when a ligand $\mathrm{L}$ is bound to the iron is a measure of the ratio of the Fe-L dissociation constants for the two oxidation states, since the Nernst equation (Eq. 2) can be rewritten as

$$
\mathrm{E}_{\mathrm{c}}^{\mathrm{o}}-\mathrm{E}^{\mathrm{o}}=-(\mathrm{RT} / \mathrm{nF}) \ln \left(K_{d}^{I I} / K_{d}^{I I I}\right)
$$

where $\mathrm{E}_{\mathrm{c}}^{\mathrm{O}}$ is the measured potential for the nitrophorin fully complexed to the ligand $\mathrm{L}$ in both oxidation states, $\mathrm{E}^{\mathrm{O}}$ is the measured potential for the nitrophorin in the absence of $\mathrm{L}$, and 
$K_{d}^{I I I}$ and $K_{d}^{I I}$ are the dissociation constants for ligand $\mathrm{L}$ from the $\mathrm{Fe}(\mathrm{III})$ and $\mathrm{Fe}(\mathrm{II})$ states of the complex, respectively.

\section{Ligand dissociation constant measurements for the Fe(III) complexes}

These measurements were carried out by adding aliquots of the chosen axial ligand to $10 \mu \mathrm{M}$ solutions of the air-stable Fe(III) nitrophorin and recording the optical spectra from 300 to 700 $\mathrm{nm}$. Because of the high ligand affinities, even under these dilute solution conditions, a significant fraction of the added ligand was bound, and so a mutually depleting model (45, 46 ) was used to analyze the data:

$$
\Delta \mathrm{A} / \Delta \mathrm{A}_{\max }=\left(\mathrm{P}_{\mathrm{t}}+\mathrm{L}_{\mathrm{t}}+K_{d}^{I I I}\right) /\left(2 \mathrm{P}_{\mathrm{t}}\right)-\left\{\left[\left(\mathrm{P}_{\mathrm{t}}+\mathrm{L}_{\mathrm{t}}+K_{d}^{I I I}\right)^{2}-\left(4 \mathrm{~L}_{\mathrm{t}} \mathrm{P}_{\mathrm{t}}\right)\right]^{0.5}\right\} /\left(2 \mathrm{P}_{\mathrm{t}}\right)
$$

where $\Delta \mathrm{A}$ is the change in absorbance at a given wavelength for a specific total ligand concentration $\mathrm{L}_{\mathrm{t}}, \Delta \mathrm{A}_{\max }$ is the change in absorbance of the fully complexed species at the same wavelength (determined by extrapolation), $\mathrm{P}_{\mathrm{t}}$ is the total protein concentration and $K_{d}^{I I I}(=1 /$ $K_{f}^{I I I}$ ) is the dissociation constant (units of fM-mM) for ligand $\mathrm{L}$ from the $\mathrm{Fe}(\mathrm{III})$ protein. Nitric oxide dissociation constant measurements were performed using aliquots of a $200 \mu \mathrm{M}$ solution of S-nitroso-N-acetyl-D, L-penicillamine (SNAP, at 98\% purity, obtained from World Precision Instruments) in ultrapure water $(18 \mathrm{~m} \Omega)$ containing EDTA $(50 \mu \mathrm{M})$, and were prepared freshly on the day of use. The protein solutions were prepared in degassed buffer containing $\mathrm{CuCl}(\sim 1 \mathrm{mM}$, Aldrich) and titrated anaerobically with SNAP, a fairly stable compound that decomposes stoichiometrically and rapidly in the presence of $\mathrm{Cu}(\mathrm{I})$ to generate $\mathrm{NO}$ and a disulfide product, allowing a much more accurate titration than working with gaseous NO (47).

\section{Kinetics of histamine binding and release}

Methods used for stopped-flow measurements have been described elsewhere and rate constants for binding and release of NO and histamine to/from the ferric form of NP2-M0D1 have been reported at $\mathrm{pH} 5$ and 8 (16). Stopped-flow measurements of histamine (Hm) binding were performed on an Olis Stopped-Flow RSM 1000 instrument. Protein solutions $(\sim 5 \mu \mathrm{M})$ in $100 \mathrm{mM}$ phosphate buffer at $\mathrm{pH} 7.5$ were rapidly mixed with an equal volume of the same buffer containing various concentrations of histamine. Using the Olis software the absorbance changes were fit with a single exponential to obtain the observed rated constants $\left(k_{o b s}\right.$ in s $\left.{ }^{-1}\right)$ at different histamine concentrations ( 2 to $42 \mu \mathrm{M}$ ) for a large number of repeated measurements. According to the histamine binding reaction described in Scheme 2, plotting $k_{o b s}$ against histamine concentration will give a slope of $k_{\text {on }}$ (second-order rate constant for histamine binding in $\mathrm{M}^{-1} \mathrm{~s}^{-1}$ ) according to the equation:

$$
k_{o b s}=k_{o n}[\mathrm{Hm}]+k_{o f f}
$$

where $[\mathrm{Hm}]$ is the histamine concentration and $k_{\text {off }}$ is the reverse rate constant (or dissociation rate constant). However, the dissociation rate constant determined by this experiment for systems with very large binding constants $\left(1 / K_{d}^{I I I}=K_{f}^{I I I}=k_{o n} / k_{o f f}\right)$ are unreliable. Rather, the dissociation rate constant $\left(k_{\text {off }}\right)$ for release of histamine from the Fe-Hm complex was determined independently by measuring the rate of the displacement reaction by NO. Protein solutions $(\sim 7 \mu \mathrm{M})$ in $100 \mathrm{mM}$ phosphate buffer at $\mathrm{pH} 5.5$ and 7.5 were titrated with histamine until fully complexed $(\sim 20 \mu \mathrm{M})$, then rapidly mixed in a cuvette with an equal volume of the same buffer, degassed with argon and saturated with $\mathrm{NO}(\sim 1.9 \mathrm{mM})$. The displacement reaction was followed at $417 \mathrm{~nm}$ using a Perkin Elmer UV/vis Lambda 19 spectrophotometer. The displacement reaction shown in Scheme 3 can be described by the equation:

$$
k_{o b s}=k_{o f f} /\left[1+\left(k_{o n}[\mathrm{Hm}] / k^{N O}[\mathrm{NO}]\right)\right]
$$


where $k_{o b s}$ is the observed first-order displacement rate constant, $k_{\text {off }}$ is the histamine dissociation rate constant, $k_{\text {on }}$ is the bimolecular rate constant for histamine binding (eq 4), $[\mathrm{Hm}]$ is the histamine concentration, $k^{N O}$ is the bimolecular rate constant for NO binding, and $[\mathrm{NO}]$ is nitric oxide concentration. In this experiment $[\mathrm{Hm}] \ll[\mathrm{NO}]\left(k_{\text {on }}[\mathrm{Hm}] / k^{N O}[\mathrm{NO}] \approx\right.$ 0.01 ); thus histamine displacement is the rate determining step and equation 5 simplifies to $k_{o b s}=k_{\text {off. }}$. The measurements were repeated a number of times and averaged. Binding constants determined by equilibrium titration were compared to those calculated from the kinetic data (at $\mathrm{pH} 7.5$ ) with very good agreement. Calculated $k_{\text {on }}$ values were determined from the measured $k_{\text {off }}$ values and the binding constants to give somewhat less precise values at $\mathrm{pH} 5.5$. The $k_{o n}$ values for NP2-M0D1 at pH 5.5 and 7.5 were of similar magnitude as those previously reported at $\mathrm{pH} 5$ and 8 (16).

\section{Results and Discussion}

\section{Mass spectrometry}

The masses of the molecular ions of NP2-M0D1 and NP2-D1A, 20,053 amu and 19,878 amu, respectively, were exactly as calculated. The mass of the D1A mutant is $175 \mathrm{amu}$ less than that of NP2-M0D1, a combination of the loss of Met- 0 and the change of Asp-1 to Ala-1. Thus E. coli is capable of cleaving Met-0 for this NP2 mutant as it does for NP4 (28) which naturally has alanine as the first amino acid of the mature protein.

\section{Spectroelectrochemical studies of NP2-D1A}

Reduction potentials are important in the mechanism of action of the nitrophorins because these proteins are stabilized in the $\mathrm{Fe}(\mathrm{III})$ state, in distinction to most other heme proteins, which are autoreduced to $\mathrm{Fe}$ (II) by any excess NO present in the solution (48). The NO binding constants for the $\mathrm{Fe}$ (III) protein are a factor of $10^{5}-10^{7}$ smaller than those for the $\mathrm{Fe}$ (II) protein at the $\mathrm{pH}$ of the tissues into which the insect spits its saliva $(\sim 7.5)(16)$. The corresponding dissociation constants $K_{d}^{I I I}$ are in the one to tens of nanomolar range (16), and the insect is thus able to have this NO released to aid in dilating the capillaries near the site of the wound. This would not be the case if the Fe(II)-NO complex were the stable oxidation state ( $K_{d}^{I I} \sim$ tens to hundreds of fM $(16,18)$ ). Thus, any stabilization of the Fe(III) over the $\mathrm{Fe}(\mathrm{II})$ state (as measured by a negative shift of the $\mathrm{Fe}^{\mathrm{III}} / \mathrm{Fe}^{\mathrm{II}}$ reduction potential) is important in allowing the insect to obtain a better blood meal, and conversely, any destabilization of the Fe(III) state (positive shift of the $\mathrm{Fe} \mathrm{III}^{\mathrm{II}} / \mathrm{Fe}^{\mathrm{II}}$ reduction potential) could prevent the insect from being able to remain long enough at the site of the bite to obtain a sufficient blood meal. Since Met- 0 is not present in the mature form of the native NP2 protein, any difference in the $\mathrm{Fe} \mathrm{e}^{\mathrm{III}} / \mathrm{Fe}^{\mathrm{II}}$ reduction potential between NP2-M0D1 and NP2-D1A must be determined and its effects understood.

In Figure 2 is shown an example of a spectroelectrochemical titration of the NO complex of NP2-D1A at pH 7.5. As can be seen, the overlapped spectra have good isosbestic points and the absorbance change at any wavelength can be fit well to the Nernst equation (Eq. 1) for a 1-electron reduction with an $\mathrm{E}^{\mathrm{o}}$ of $-20 \mathrm{mV}( \pm 2 \mathrm{mV} v s$. SHE). The spectral changes during the titration are identical to those observed for wild-type recombinant NP2 (-M0D1) published earlier (16), and thus the D1A mutation does not cause any change in the optical spectra from those observed for NP2-M0D1. The Fe $\mathrm{Fe}^{\mathrm{III}} / \mathrm{Fe}^{\mathrm{II}}$ reduction potentials of the D1A mutant in the absence and presence of enough added axial ligand (NO, histamine, imidazole) to completely form the NP2-D1A(L) complexes are summarized in Table 1, together with the data already reported for wild-type recombinant NP2-M0D1 and its same ligand complexes at $\mathrm{pH} 5.5$ and $7.5(14,16,18)$, and those measured in this work for the mutant NP2-GSHM0D1 at pH 7.5. As can be seen, the NP2-D1A mutation has only very minor effects on the $\mathrm{Fe}^{\mathrm{III}} / \mathrm{Fe}^{\mathrm{II}}$ reduction potentials of the protein in the absence of added ligands and in the presence of each of the three ligands studied. The NP2-GSHM0D1 construct has more significant differences in $\mathrm{Fe} e^{\mathrm{III}} / \mathrm{Fe}^{\mathrm{II}}$ 
reduction potential, most notably a significantly more negative reduction potential without added ligand. The presence of the uncleaved residues at the N-terminus (GSHM) in this case stabilizes the ferric state due to the proximity of these residues at the entrance to the heme binding pocket, where it is possible that the histidine of the GSHM extension may interact by $\mathrm{H}$-bonding to one of the heme carboxylates that protrudes from the mouth of the heme binding pocket (Figure 1 top).

\section{Ligand binding constants}

As reported previously (18), it is convenient to measure the ligand dissociation constants of the Fe(III) protein, $K_{d}^{I I I}$, and then use equation (2) and the reduction potential for the ligandbound complex to calculate the binding constant for the Fe(II) protein, $K_{d}^{I I}$, because of the oxygen sensitivity of the $\mathrm{Fe}$ (II) protein, and, in the case of $\mathrm{L}=\mathrm{NO}$, the extreme stability of the $\mathrm{Fe}(\mathrm{II})-\mathrm{NO}$ complex. An example of the data obtained for $\mathrm{NO} K_{d}^{I I I}$ measurement at $\mathrm{pH} 7.5$ is shown in Figure 3. The results of the dissociation constant measurements for NP2-D1A complexes are summarized in Table 1, where the values of $K_{d}^{I I I}$ and $\mathrm{E}_{\mathrm{c}}^{\mathrm{o}}$ are utilized to calculate the values of $K_{d}^{I I}$ from Equation 2, which are also included in this table. (In the Supporting Information, Table S1, the corresponding formation constants, values of $\log K_{f}^{I I I}$ and $\log$ $K_{f}^{I I}\left(=p K_{d}^{I I I}\right.$ and $\left.p K_{d}^{I I}\right)$, are given in units of $\log \mathrm{M}^{-1}$ for the benefit of those who prefer this presentation of the results.) As can be seen, the dissociation constants for the Fe(III) complexes are very similar or within experimental error for NP2-M0D1, NP2-GSHM0D1 and the NP2D1A mutant. Nevertheless, because of the small differences in the $\mathrm{E}^{\mathrm{o}}$ values for the NP2-D1A mutant (relative to NP2-M0D1) and larger differences for NP2-GSHM0D1, the calculated log $K_{d}^{I I}$ values are slightly different. This is most apparent for the histamine and imidazole complexes for the D1A mutant, where we see that the Fe(II) complexes are slightly more stable at both pH 5.5 and 7.5; thus, the D1A mutation stabilizes the histamine and imidazole complexes of the $\mathrm{Fe}$ (II) form. However, this is not the physiologically-relevant oxidation state of this protein, or the one that would be present in the tissues when the platelets and mast cells of the victim of the bite begin to secrete histamine. Thus this increase in complex stability probably has no significant effect on the physiological mechanism of action of NP2-D1A.

\section{NMR spectroscopy}

The NMR spectra of both high-spin and low-spin complexes of NP2-M0D1 and NP2-D1A differ markedly, both in the ratio of heme orientational isomers A:B, Scheme 4, and also in the pattern of shifts observed, and hence in the H57 imidazole plane orientation for high-spin NP2, and both axial ligand plane orientations for low-spin NP2. In Figure 4A and B are shown the $1 \mathrm{D}{ }^{1} \mathrm{H}$ NMR spectra of high-spin NP2-M0D1 and NP2-D1A, recorded at $\mathrm{pH} 7.0$ at $25^{\circ} \mathrm{C}$, which had each been equilibrated for several hours. In Supporting Information Figure S1 is shown a comparison of the $1 \mathrm{D}{ }^{1} \mathrm{H}$ NMR spectra of high-spin NP2-M0D1 and NP2-GSHM0D1 recorded at $30{ }^{\circ} \mathrm{C}$ at $600 \mathrm{MHz}$ after one day's equilibration in $90 \% \mathrm{H}_{2} \mathrm{O}, 10 \% \mathrm{D}_{2} \mathrm{O}$, where it can be seen that although the chemical shifts are slightly different, the pattern of heme resonances is extremely similar for the two proteins, and that the $\mathbf{A}: \mathbf{B}$ heme orientation ratio is also very similar for the two.

Thus the 1D ${ }^{1} \mathrm{H}$ NMR spectra of NP2-M0D1 and NP2-GSHM0D1 (Supporting Information Figure S1) are extremely similar, while that of NP2-D1A is markedly different (Figure 4B as compared to 4A). Furthermore, NP2-D1A readjusts its A:B heme orientation ratio very slowly. And because it does not show any changes in chemical shifts with time, the changes in peak intensities provide a good opportunity for studying both isomers in the same protein environment. Using saturation transfer techniques and the assignment of the low-spin NMeIm complex $\mathbf{A}$ and $\mathbf{B}$ isomers discussed below, as we have shown previously (19), it is possible to assign the heme methyl resonances of the high-spin NP2-D1A complex (not shown), which are labeled in Figure 4A. The 6,7-propionates and 2,4-vinyl groups of both the $\mathbf{A}$ and $\mathbf{B}$ heme 
rotational isomers of the high-spin complex (Scheme 4) can be assigned from a NOESY spectrum of the high-spin complex itself, as shown in Figure 4B and C. The assignments are summarized in Table 2. From these assignments and the plot of expected heme methyl shift vs. angle of the H57 imidazole plane (49), Supporting Information Figure S2, which is based on the effect of that imidazole plane on the orientation of the $\pi$ orbital of the heme that is involved in spin delocalization from the high-spin Fe(III) center to the porphyrin ring, as well as the much smaller effect of the pseudocontact shift, which is determined by the orientation of the heme magnetic axes $(19,50)$, it is possible to estimate the orientation of that ligand plane for the two isomers as $135^{\circ}$ for $\mathbf{A}$ and $136^{\circ}$ for $\mathbf{B}$. Those same values were found to be slightly larger, $\sim 137^{\circ}$ for $\mathbf{A}$ and exactly $135^{\circ}$ for $\mathbf{B}$ of NP2-M0D1 (20). (It should be noted that because the chemical shifts of 5Me and 8Me are coincident for A of NP2-D1A and $\mathbf{B}$ of NP2-M0D1, we know that the angle is $135^{\circ}$ in both cases, because at this angle the $5 \mathrm{Me}$ and $8 \mathrm{Me}$ lines of Supporting Information Figure S2 cross each other. And if the chemical shift of $5 \mathrm{Me}$ is greater than $8 \mathrm{Me}$, as is the case for B of NP2-D1A, but the reverse for A of NP2-M0D1, then the angle is less than $135^{\circ}$ for the former, and greater than $135^{\circ}$ for the latter.) Although the differences are small, they are measureable, and lead to somewhat different chemical shifts for the NP2D1A mutant protein, Table 2.

The 1D, WEFT-NOESY and HMQC spectra of the NMeIm complex of NP2-D1A at pH 7.0 and the temperatures listed are shown in Figure 5. Both $\mathbf{A}$ and $\mathbf{B}$ heme orientational isomers are observed, and the resonances of both can be assigned, except for meso- $\beta-\mathrm{H}$ of the $\mathbf{A}$ isomer. The ligand N-Me resonances observed at 16.0 and $16.5 \mathrm{ppm}$ clearly show that the A:B ratio (Scheme 4) is approximately 1:3 for this complex at this point in time. Based on these wellseparated N-Me resonances for the NP2-D1A complex we can conclude that the two N-Me, 6,7- $\mathrm{CH}_{2}$ and other resonances observed for the NMeIm complex of NP2-M0D1 reported previously (19) were due to the presence of the two heme orientational isomers, in an approximate ratio of 1:3. At the time of publication of that work we did not realize that the $\mathbf{A}: \mathbf{B}$ ratio changed as a function of both axial ligand and time. The assignments are presented in Table 3. Using these assignments at $32{ }^{\circ} \mathrm{C}$, and the plot of the relative heme methyl resonances as a function of the orientation of the plane of the axial ligand(s) $(49,50)$ shown in Supporting Information Figure S3, the average nodal plane (average of the histidine and exogenous imidazole planes) appears to be $158-162^{\circ}$ for the $\mathbf{B}$ isomer of NP2-D1A, as compared to $163^{\circ}$ for the $\mathbf{B}$ isomer of NP2-M0D1 (19). (It should be noted that because the $3 \mathrm{Me}$ resonance crosses the $5 \mathrm{Me}$ and $1 \mathrm{Me}$ resonances at the angles $158.5^{\circ}$ and $162^{\circ}$, respectively (Supporting Figure S3), it is possible to be quite precise about the ligand orientation in this region of the plot; the same would not be true at other angles.) Thus the histidine and exogenous imidazole planes of the $\mathbf{B}$ rotational isomer are oriented similarly but not exactly the same for the NMeIm complexes of the two proteins.

In like manner the 1D and 2D NMR spectra of NP2-D1A-ImH (A:B ratio 1:2 at this point in time, Scheme 4) were investigated by WEFT-NOESY and HMQC spectroscopy, as shown in Supporting Figure S4. The chemical shifts of the $\mathbf{A}$ and $\mathbf{B}$ isomers are listed in Supporting Information Table S2. For these complexes, the average nodal plane of the $3 e(\pi)$ orbital involved in spin delocalization (found for NP2-M0D1-ImH to be the average angle of the H57 and exogenous ImH planes (19)) appears to be $\sim 151-154^{\circ}$ for the $\mathbf{B}$ rotational isomer, as compared to $149.6^{\circ}$ from the crystal structure of the $\mathbf{B}$ rotational isomer of NP2-D1 A-ImH (PDB file 2ASN) (Weichsel, A.; Berry, R. E.; Zhang, H.; Walker, F. A.; Montfort, W. R., to be submitted), and $\sim 110-118^{\circ}$ for the $\mathbf{A}$ rotational isomer, a larger range because the resonances are widely spaced and far from crossover points (Supporting Information Figure S3). The calculated average nodal plane angle for the $\mathbf{A}$ isomer based on the crystal structure (where the $\mathbf{A}$ isomer was actually not detected) is expected to be $120.4^{\circ}$. Taking the NMeIm and ImH ligand complexes together, we conclude from the NMR data that the heme seating is slightly 
different for the $\mathbf{A}$ and $\mathbf{B}$ heme orientational isomers of both complexes of NP2-M0D1 and NP2-D1A.

\section{NMR studies of the rate of NP2-D1A ferriheme A:B ratio equilibration}

The two isomers (A and B, Scheme 4) have different NMR spectra because of (a) different protohemin orientations (2-vinyl/3-methyl, 1-methyl/4-vinyl and their interactions with different protein side chains in the two isomers), and a possible difference in hemin "seating" for the two, (b) axial ligand orientation(s) $(17,19)$ and (c) heme ruffling (21). According to all of the crystal structures of NP1 $(14,25)$, NP4 $\left(28^{-32}\right)$ and NP2 (26, Weichsel, A.; Berry, R. E.; Zhang, H.; Walker, F. A.; Montfort, W. R., to be submitted), the H59 (H57) imidazole plane of both $\mathbf{A}$ and $\mathbf{B}$ isomers is oriented close to $135^{\circ}$ from the $\mathrm{N}_{\mathrm{II}}-\mathrm{Fe}-\mathrm{N}_{\mathrm{IV}}$ axis, measured in the direction of the $\mathrm{N}_{\mathrm{I}}-\mathrm{Fe}-\mathrm{N}_{\mathrm{III}}$ axis. If the heme is simply turned over, then an angle $\varphi_{\mathrm{A}}$ of 135 $-\Delta$ would become $\varphi_{B}=135+\Delta$, all other things being equal. Likewise, the bound exogenous ligand is expected (to first order) to be oriented the same, independent of heme rotational orientation, and thus the average imidazole nodal plane angle is expected to be the same, all other things equal. But we see deviations from these predicted angles that indicate a small difference in hemin seating for the $\mathbf{A}$ and $\mathbf{B}$ isomers.

A difference in ferriheme center structure for the $\mathbf{A}$ and $\mathbf{B}$ (Scheme 4) isomers means first of all that we should expect different physical/chemical properties such as 1 ) $\mathrm{Fe}^{\mathrm{III}} / \mathrm{Fe}^{\mathrm{II}}$ reduction potentials for the $\mathbf{A}$ and $\mathbf{B}$ isomers and 2) exogenous ligand binding constants. 1) For the case of $\mathrm{Fe}^{\mathrm{III}} / \mathrm{Fe}^{\mathrm{II}}$ reduction potentials for the $\mathbf{A}$ and $\mathbf{B}$ isomers, this difference is expected to be small and difficult to detect, as reported some years ago for the $\mathbf{A}$ and $\mathbf{B}$ isomers of bovine liver microsomal cytochrome $b_{5}$, where the extrapolated difference in $\mathrm{E}^{\mathrm{O}}$ for $100 \% \mathbf{A}$ and $100 \%$ B was calculated to be $27 \pm 4 \mathrm{mV}$ (51). Such a small contribution from the minor isomer of NP2-M0D1 (<11\% A), with small difference in reduction potential, would be very difficult to observe. 2) For the case of ligand dissociation constants, a very small contribution from the minor isomer could explain why we do not observe a second binding curve, or in the extreme, the dissociation constant might be so different that it is not observed over the ligand titration range. To determine what difference in ligand binding we should observe, let us consider that there is an equilibrium between the $\mathbf{A}$ and $\mathbf{B}$ isomers in the high-spin proteins that depends on the heme center structure and is characterized by an equilibrium constant $K_{H S} \equiv \mathrm{R}_{\mathrm{HS}}=[\mathrm{PB}] /$ [PA], where [PA] and [PB] are the equilibrium concentrations of isomers $\mathbf{A}$ and $\mathbf{B}$ inside the heme cavity of the protein (equilibria I); $K_{H S} \equiv \mathrm{R}_{\mathrm{HS}}$ thus depends on the relative stabilities of the two isomers in the heme binding cavity. High-spin NP2-M0D1, NP2-GSHM0D1 and NP2D1A have equilibrated hemin $\mathbf{A}: \mathbf{B}$ ratios of $1: 8,1: 8$ and 1:14, respectively (thus $R_{H S}=8,8$ and 14 , respectively). The different $R_{H S}$ values show that the $\mathbf{B}$ isomer is even more stable for the D1A mutant than for the wild-type recombinant protein and the GSHMOD1 mutant protein. After axial ligand addition a new equilibrium condition (equilibra II) is reached after some time (this time to reach equilibrium depends on a number of factors including concentration of ligand, its binding constant and the heme dissociation rate for the protein):

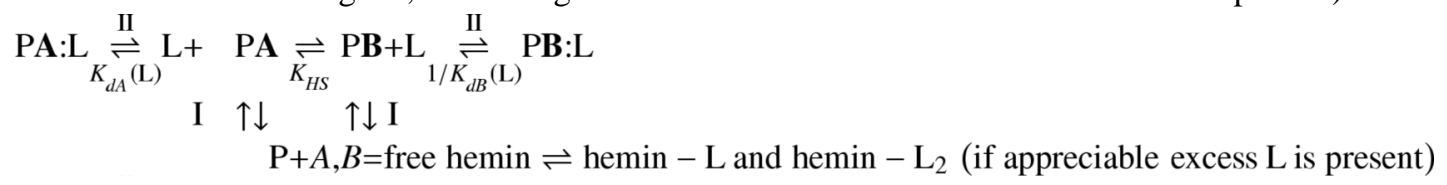

If $K_{d B}(\mathrm{~L})=K_{d A}(\mathrm{~L})$ then $\mathrm{R}_{\mathrm{LS}}(\mathrm{L})=[\mathrm{PB}: \mathrm{L}] /[\mathrm{PA}: \mathrm{L}]=\mathrm{R}_{\mathrm{HS}}$, since $K_{d B}(\mathrm{~L}) / K_{d A}(\mathrm{~L})=\mathrm{R}_{\mathrm{HS}} / \mathrm{R}_{\mathrm{LS}}(\mathrm{L})$ at equilibrium, but if $\mathrm{R}_{\mathrm{LS}}(\mathrm{L}) \neq \mathrm{R}_{\mathrm{HS}}$, then $K_{d B}(\mathrm{~L}) \neq K_{d A}(\mathrm{~L})$. This allows us to explain different ratios for different low-spin complexes, and shows that $\mathrm{R}$ can be used as an indicator of the difference in binding affinity of hemin for the $\mathbf{A}$ and $\mathbf{B}$ isomers of the nitrophorins. In general, we have found that for NP1 and NP4, $\mathrm{R}_{\mathrm{LS}}(\mathrm{L}) \approx \mathrm{R}_{\mathrm{HS}}$ (varying from 1 to 2 , thus $K_{d B}(\mathrm{~L}) \approx$ $\left.K_{d A}(\mathrm{~L})\right)(20,21)$, while for NP2-M0D1, $\mathrm{R}_{\mathrm{LS}}(\mathrm{L})<\mathrm{R}_{\mathrm{HS}}$ is observed for some ligands (varying 
from 8 to 4 for NP2-M0D1, thus $\left.K_{d B}(\mathrm{~L})>K_{d A}(\mathrm{~L})\right)$ (20); as we will show below, for NP2-D1A, $\mathrm{R}_{\mathrm{LS}}(\mathrm{L})>\mathrm{R}_{\mathrm{HS}}$ (thus $K_{d B}(\mathrm{~L})<K_{d A}(\mathrm{~L})$ for NP2-D1A).

A freshly prepared sample of NP2 will in theory start with a pre-equilibrium A:B ratio of 1:1 before equilibrating to the most stable ratio. Since it takes some time to purify the nitrophorin (after hemin is added to the apoprotein) before measurements can be performed on the sample, we do not observe this initial ( $\mathrm{t}_{0}$ ) pre-equilibrium A:B (statistical) ratio. For NP2-M0D1 (high spin) the equilibration of the $\mathbf{A}: \mathbf{B}$ ratio is so rapid (on the order of just a few hours) that only the final equilibrated ratio (1:8) is normally observed (even though the purification is done at lowered temperatures). To observe the pre-equilibrium $\mathbf{A}: \mathbf{B}$ ratio, hemin must be titrated into the purified apoprotein so that it is possible to observe the ratios quickly; nevertheless, typically it is not usually possible to obtain the NMR spectrum until about $30 \mathrm{~min}$ after hemin addition, and by this time NP2-M0D1 has already equilibrated significantly to a ratio of $\sim 1: 4$ or more (equilibrium ratio 1:8); the same is true of NP2-GSHM0D1. This is not the case for NP2-D1A, which does not reach its equilibrium $\mathbf{A}: \mathbf{B}$ ratio for many days, and thus pre-equilibrium $\mathbf{A}: \mathbf{B}$ ratios can be (and are) observed.

A freshly prepared sample of NP2-D1A (after heme addition, purification via FPLC, concentration and $\mathrm{D}_{2} \mathrm{O}$ exchange, all at $4^{\circ} \mathrm{C}$ ) had an $\mathbf{A}: \mathbf{B}$ ratio of 1:1.8. After 4 days at $\mathrm{RT}$ the ratio was $\sim 1: 5$; after 1 month at $4{ }^{\circ} \mathrm{C}$ the ratio $\mathrm{R}_{\mathrm{HS}}$ was $1: 7.6$, and after 3 months the sample had apparently reached the equilibrium $\mathbf{A}: \mathbf{B}$ ratio of 1:14 ( 7\% $\mathbf{A})$. With an exogenous ligand bound to produce low-spin NP2-D1A(L), the equilibration rates are even slower because of very small remaining concentration of the high-spin complex, Equation (6), and in some cases the $\mathbf{A}: \mathbf{B}$ ratio was kinetically trapped (vide infra). These simple experiments, using $1 \mathrm{D}^{1} \mathrm{H}$ NMR spectroscopy to estimate the $\mathbf{A}: \mathbf{B}$ ratio as a measure of protein equilibration in the highand low-spin complexes, are not as precise as measurement of rate constants by stopped-flow kinetics, for example, but they can nevertheless provide some useful qualitative kinetic data (the error in estimating the $\mathbf{A}: \mathbf{B}$ ratio by NMR integrations is probably about $\pm 2-3 \%$ in most cases, but could be as high as $\pm 5 \%$ when the intensities of the two are very different). For the high-spin sample of NP2-D1A discussed above, fitting the estimated A:B ratios (as mole fraction of $\mathbf{A}$ ) at RT to a simple first order decay to the equilibrium ratio of 1:14, we obtain a half-life of about $43 \mathrm{hr}$ or 1.8 days.

Half of the fresh sample of high-spin NP2-D1A prepared above (with a measured preequilibrium A:B ratio of 1:1.8) was used to prepare three exogenous ligand-bound (imidazole, cyanide and $\mathrm{N}$-methylimidazole) low-spin samples, for which the pre-equilibrium $\mathbf{A}: \mathbf{B}$ ratios were measured at different time intervals (samples hereafter denoted as \#1). Table 4 summarizes the pre-equilibrium low-spin hemin A:B ratios for NP2-D1A-L as a function of time. In preparation of the low-spin hemin complexes only a small excess of each ligand was used (except for cyanide, for which it was important not to add any more ligand than necessary to observe the disappearance of the high-spin hemin ${ }^{1} \mathrm{H}$ NMR signals, in order to avoid formation of some of the bis-cyanide complex outside the heme binding pocket; absence of the bis-cyanide complex ( $\mathrm{g}_{\max }=3.75$ as compared to $\mathrm{g}_{\max }=3.35-3.45$ for the histidine-cyanide ligand combination (21)) at very low temperatures, where $K_{d}^{I I I}$ values are extremely small for both complexes was confirmed by EPR spectroscopy). The NP2-D1A(CN) NMR spectra and assignments for this part of the work are shown in Supporting Information Figure S5 and Table S3, respectively.

The other half of the above-discussed high-spin sample with $\mathbf{A}: \mathbf{B}=1: 1.8$ was allowed to equilibrate for 4 days at room temperature before preparing the same low-spin complexes and measuring their pre-equilibrium $\mathbf{A}: \mathbf{B}$ ratios at different time intervals (columns marked $\# 2$ in Table 4) starting from a different initial A:B ratio. The pre-equilibrium A:B ratios, column \#1, for the ligand $\mathrm{N}$-methylimidazole (NMeIm) do not change significantly over the 11 days of 
the experiment. Rather, they remain constant at about 1:1.8, and likewise the ratios in column $\# 2$ do not change significantly from their initial ratio on day 4 ( 1:5). Clearly the equilibration rate in the presence of a small excess of NMeIm is extremely slow, so that effectively the hemin A:Bratio is kinetically trapped at a non-equilibrium value by the ligand (at the ligand concentration used for these samples). For cyanide the case appears to be the same, with the ratio in column \#1 remaining effectively constant at the initial A:B ratio (about 1:1.8). But for the sample of column \#2, although it started at a ratio of about 1:5 the sample then continued to equilibrate slowly (half-life of $\sim 14$ days). This is likely due to the presence of a slightly less than stoichiometric amount of cyanide in this particular sample, which would result in a small amount of high-spin NP2-D1A being present, which would allow an 'escape route' to make it possible for the $\mathbf{A}$ and $\mathbf{B}$ forms to continue to exchange and approach equilibrium. Binding of an exogenous ligand to the hemin provides a significant kinetic barrier to heme rotation, since strong ligand binding contributes significantly to holo-protein stabilization. (A significant $\Delta \mathrm{G}$ would be associated with removing heme and ligand from the protein pocket to enable heme rotation.) It is therefore reasonable to assume that the $\mathbf{A}$ and $\mathbf{B}$ forms cannot exchange as lowspin complexes on a relevant timescale.

Thus in the presence of a sufficiently high concentration of ligand, such that the concentration of high-spin ferriheme protein is effectively zero, the $\mathbf{A}: \mathbf{B}$ ratio will be kinetically 'trapped' at whatever ratio was present before ligand was added, or whatever ratio to which it was driven by pre-equilibrium kinetics (if the ligand association rate for one of the isomers were significantly greater). The time required for the low spin complex $\mathbf{A}: \mathbf{B}$ ratio to reach equilibrium thus depends on the high-spin complex equilibration rate, and will therefore strongly depend on ligand concentration and the dissociation constant for the ligand (since these will dictate the high-spin complex concentration).

The dissociation constant for $\mathrm{CN}^{-}$from NP2-M0D1 and NP2-D1A is too small to measure, with estimated $\left.K_{d}^{I I I}(\mathrm{CN})<3 \mathrm{nM}\right)$, while it is larger for NMeIm $\left(K_{d}^{I I I}(\mathrm{NMeIm})=27 \mathrm{nM}\right.$, Table 1) and $\operatorname{ImH}\left(K_{d}^{I I}(\operatorname{ImH})=40 \mathrm{nM}\right.$, Table 1). Thus it is clear that the behavior of samples \#1 and \#2 of Table 4 does not depend on the size of $K_{d}^{I I I}(\mathrm{~L})$, but rather on the exact ligand concentration in each sample. For a low-spin sample to reach equilibrium there must be insufficient ligand concentration to cause the ratio to be 'trapped', but not so little that there is detectable high-spin complex present such that the ratio does not reflect the true low spin equilibrated ratio. This appears to be the case for imidazole-bound low-spin samples in Table 4 , in which the concentration of high-spin complex is not observable in the NMR spectrum, but the hemin $\mathbf{A}$ and $\mathbf{B}$ forms still exchange on a reasonable timescale (if somewhat slower than the high-spin complex, with a half life of 4-5 days) until they reach equilibrium. In the preparation of the low-spin samples for NMR study it is difficult to produce exactly the same ligand concentration each time when a ratio of NP:L very close to 1:1 is desired; for large equilibrium constants, small differences in the concentration of free ligand will strongly affect the rate of A:B interconversion. Thus the half-life for each column of Table 4 differs (not shown), although the final equilibrated ratio is the same for both columns. The imidazole and cyanide complexes of NP2-D1A equilibrate (by extrapolation) to a final A:B ratio of about $1: 22$ and $1: 23$, respectively. This represents a relatively small difference in the equilibrium concentration of $\mathbf{A}$ from that observed for the high spin form (1:14), and thus the ligand binding constants to the $\mathbf{A}$ and $\mathbf{B}$ isomers appear to be similar, although there is probably a significant error in these estimates of equilibrium ratios. In the case of these two ligands the minor $\mathbf{A}$ isomer would not be observable in the ligand binding titrations discussed above. For imidazole $\left(\mathrm{R}_{\mathrm{LS}}(\mathrm{L}) \approx 22\right)$ the calculated dissociation constant is about $40 \%$ larger for the $\mathbf{A}$ isomer than for the major $\mathbf{B}$ isomer, a value close to the experimental error for measuring the $K_{d}^{I I I}$ values by equilibrium spectrophotometric titration (Table 1). 
Thus the rate of heme reorientation, measured by NMR spectroscopy, provides an excellent means of monitoring the openness of the mouth of the heme pocket and the dynamics of the loops that form that mouth of the nitrophorins.

\section{Histamine binding and release kinetics measurements}

As discussed above, different equilibration constants for the $\mathbf{A}$ and $\mathbf{B}$ forms must result in different ligand kinetics for the two forms ( between forms $\mathbf{A}$ and $\mathbf{B}$ is slow with respect to the measured ligand on/off kinetics, two independently observable rate constants should exist for $k_{\text {on }}$ and $k_{\text {off. }}$. If the contribution from the $\mathbf{A}$ form is observable (sufficient relative concentration and not too large or too small a difference in rate constant), then the observed kinetic data will only be fit with two exponentials; in other words it should be biphasic. For the histamine kinetics measured in this work for NP2-M0D1 and NP2-D1A, we could not observe a second phase distinguishable from the noise. At equilibrium NP2-M0D1 and NP2-D1A have A:B ratios of 1:8 and 1:14, respectively (at $\mathrm{pH} 7.5$ without added ligand). Thus ideally we expect an $11 \%$ and $7 \%$ contribution from the $\mathbf{A}$ isomer, for NP2-M0D1 and NP2-D1A, respectively. We can only assume that at the conditions we used to measure the histamine rate constants there was not sufficient difference between the rates for the two isomers to be able to distinguish the small contribution from the minor isoform of NP2 (form $\mathbf{A}$ ). Thus, the contribution from the $\mathbf{A}$ form of NP2-M0D1 and NP2-D1A (for our preparations and at the pH used) was very small and was not observed in our kinetics or equilibrium titration measurements. Previously-reported kinetics for the nitrophorins at different $\mathrm{pH}$ values observed biphasic kinetics, but for NP2MOD1 the contribution from the second phase was quite small (16).

An example of the stopped-flow kinetics of histamine binding and release is shown in Figure 6, where histamine dissociation from NP2-M0D1 and NP2-D1A at $\mathrm{pH} 7.5$ can each be fit with a single exponential and histamine binding rates at various histamine concentrations can be plotted to yield a straight line. The histamine kinetics results summarized in Table 5 clearly show that NP2-D1A releases histamine $\left(k_{\text {off }}\right)$ a factor of 1.6 more slowly than NP2-M0D1 at $\mathrm{pH} 5.5$, and a factor of 5 more slowly at $\mathrm{pH} 7.5$, where histamine would be present at the site of the insect bite. Histamine also binds to NP2-D1A $\left(k_{o n}\right)$ a factor of 1.6 more slowly at $\mathrm{pH}$ 5.5 and a factor of 2.5 more slowly at $\mathrm{pH}$ 7.5. The histamine dissociation constants $\left(K_{d} \mathrm{~s}\right)$ for NP2-M0D1 and NP2-D1A determined by ligand equilibrium titration were the same (within the experimental error for those experiments, Table 1), but the dissociation constants obtained from the kinetics experiments (from $K_{d}^{I I I}=k_{o f f} / k_{o n}$ ) can be determined with much smaller experimental error, and are thereby able to reveal that the histamine complex of NP2-D1A is slightly more stable (factor of 2) than that of NP2-M0D1. The slower on and off kinetics observed for histamine with NP2-D1A as compared to NP2-M0D1 are consistent with the slower kinetics observed for heme leaving and entering the pocket. It is thus likely that the AB loop (the protein loop between the A and B $\beta$-strands) is able to close over the heme binding pocket when the N-terminal methionine is not present to hinder it, as is the case for NP4-NO $(27,28)$, and that this slows passage of both heme and ligands in and out of the pocket. Consistent with this, the structure of NP2-M0D1 (PDB file 1EUO, $\mathrm{P}_{1}{ }_{1}{ }_{1} 2$ space group), shown in Figure 7, top, has the bulky Met-0 blocking the region between residue D1 and the A-B loop (L28-Y38), with that loop in a conformation that leaves D31 completely hidden, for example, while the latest structure of NP2-D1A, of the ammonia complex (PDB file 2EU7, $\mathrm{P} 2{ }_{1} 2_{1} 2$ space group), shows the protein with a closed loop with different residues (D31-V34) prominently displayed, as shown in Figure 7, middle. This loop conformation of NP2-D1A( $\left.\mathrm{NH}_{3}\right)$ is not the same as that of NP4(NO), shown in Figure 7, bottom $(27,28$ ) (there is no hydrogen-bond between the N-terminal amino group and the glutamate (E32) in the A-B loop of NP2-D1A, because in NP2 that residue is an aspartate (D31) and the side chain is too short to form the Hbond). Nevertheless it is clear that the opening to the heme pocket is similarly closed as that 
of NP4(NO), and significantly more closed than that of NP2-M0D1, which would clearly slow the passage of constituents (hemin, histamine, and possibly also NO) in and out of the heme pocket.

\section{Implications of the slow A/B kinetics of NP2-D1A}

Since none of the native nitrophorin proteins found in the R. prolixus salivary gland has an Nterminal methionine (because the mature proteins are produced by proteolysis of a leader sequence, Scheme 1), the mixture of proteins produced in the cells of the salivary glands, bound to heme and then to NO, and stored there for up to a month between feedings $(3,4)$, will likely be trapped with non-equilibrium $\mathbf{A}: \mathbf{B}$ ratios. This is because all four of the nitrophorins should be able to make the closed loop form seen in the crystal structures of NP4-NO $(27,28)$, Figure $1 \mathrm{a}, \mathrm{b}$, and the ammonia complex of NP2-D1A, Figure 7 middle, for which we find that the NP2-D1A mutant has much slower kinetics of heme rotation and histamine binding and release than the recombinant protein containing the Met- 0 and an equilibrium $\mathbf{A}: \mathbf{B}$ ratio different from 1:1 (native mature NP2 and probably NP3 as well, although we have not investigated the rates of heme rotation for NP3). Because of the similarity of NP2-M0D1 and NP2-GSHM0D1 in equilibrium properties ( $K_{d}^{I I I} \mathrm{~s}, \mathrm{Fe}^{\mathrm{III}} / \mathrm{Fe}^{\mathrm{II}}$ reduction potentials and hemin $\mathbf{A}: \mathbf{B}$ equilibrium ratios) and in the rate of $\mathbf{A}: \mathbf{B}$ equilibration, we can conclude that the presence of M0 has the same or similar effect as the presence of a longer $\mathrm{N}$-terminal peptide such as GSHM0, and likely similar to the unprocessed native NP2 containing the leader sequence that targets the protein for export, in that in all of these cases the $\mathrm{N}$-terminal aspartate group is blocked by a bulky residue or residues from helping to stabilize the closed loop form of the protein (Figure 7 top). Thus, NP2-D1A has given us our first look at the equilibrium A:B ratio expected for the mature protein and the time required to reach it, and the rate of heme reorientation in NP2-D1A as compared to NP2-M0D1 provides an excellent means of monitoring the openness of the mouth of the heme pocket. NP4, the only nitrophorin that has an alanine as the first amino acid of the mature native protein, when expressed in E. coli has M0 cleaved naturally by enzymes available in the cells of that organism. Unfortunately, NP4 is rather temperamental with respect to remaining monomeric in solution (52, Berry, R. E.; Shokhireva, T. Kh.; Walker, F. A., to be submitted); among the NMR spectra of high-spin NP4 recorded over the past several years we have noted some variation in $\mathbf{A}: \mathbf{B}$ ratio, although we have not investigated this systematically. However, based on our findings for NP2-D1A we can expect that the rate is slow for NP4 as well.

The observed equilibrium A:B ratio for recombinant NP1 (with its M0K1 amino acid sequence intact) is close to $1: 1$ for all of its complexes (1.1:1 for NP1-CN by NMR spectroscopy(21)), but that for NP4 (without Met-0) is somewhat different ( 2:1 for NP4-CN by NMR spectroscopy (21)); in contrast, those for NP2-M0D1(L) and NP3-M0D1(L) are quite different from 1:1. The kinetics of NO release measured earlier (16) (on samples most probably already at the equilibrium $\mathbf{A}: \mathbf{B}$ heme rotational isomer ratio) were observed to be biphasic for all four of the nitrophorins, suggesting to us a difference in $k_{\text {off }}$ for the two hemin rotational isomers of each. The ratio of fast:slow phases (as determined from the $\%$ of NO released by the fast phase) (16) is similar in each case to the equilibrium ratio of $\mathbf{B}: \mathbf{A}(50: 50=1: 1$ for NP1 (1.1:1 by NMR $(20,21)), 39: 61 \approx 1: 1.56$ for NP4 $(1: 2$ by NMR $(20,21)), 96: 4=24: 1$ for NP2-M0D1 (8:1 for high-spin (20) and 4:1 for the cyanide complex by NMR (21)), and 80:20=4:1 for NP3 (4:1 for the high-spin complex by NMR (20)). Thus, assuming the $\mathbf{B}$ isomer has the faster NO release kinetics (although the opposite might in principle be true for NP1 and NP4), the differences in equilibrium $\mathbf{A}: \mathbf{B}$ ratio and rates of $\mathrm{NO}$ release for each of the isomers of each of the nitrophorins provide kinetic data that are probably not representative of the nitrophorins in the salivary glands of the insect, where the proteins are likely kinetically trapped by NO binding, with non-equilibrium $\mathbf{A}: \mathbf{B}$ hemin ratios. This non-equilibrium ratio of hemin orientations likely leads to a different $\mathrm{NO}$ time-release profile than suggested by the kinetics 
measured on in vitro samples with equilibrium A:B ratios. Since recombinant NP1 and NP3 as produced in this and the Montfort laboratories also both contain the M0 from expression initiation, mutants such as NP1-K1A and NP3-D1A should be prepared and investigated by the techniques used in this study. Then the kinetics of NO and histamine binding and release of all four nitrophorins, both samples freshly reconstituted with hemin, and with fully equilibrated A:B ratio should be measured and compared. Only then will it be possible to make conclusions as to the physiological consequences of kinetic trapping of non-equilibrium hemin ratio on the profiles for release of $\mathrm{NO}$ and binding of histamine by the physiological mixture of the four nitrophorins.

\section{Supplementary Material}

Refer to Web version on PubMed Central for supplementary material.

\section{Acknowledgements}

The authors thank Mary T. Flores for preparation of the figures.

\section{Abbreviations}

The abbreviations used are:

$\mathrm{NP}$, nitrophorin

NO, nitric oxide

NMR, nuclear magnetic resonance

EPR, electron paramagnetic resonance

NP2-M0D1, recombinant NP2 with the expression-initiation methionine present before the first amino acid (aspartic acid-1) in the native protein

NP2-D1A, recombinant NP2 with the first amino acid of the native protein replaced by alanine, which allows removal of Met-0 during expression of the recombinant protein

SNAP, S-nitroso-N-acetyl-D,L-penicillamine

ImH, imidazole

Hm, histamine

$\mathbf{A}$ and $\mathbf{B}$ heme orientations, defined by looking down on the heme with H59(57) behind the heme, the substituents on the periphery of the heme are numbered clockwise for isomer $\mathbf{A}$ from 1-methyl to 8-methyl, with the propionates being at positions 6 and 7, and counterclockwise for isomer $\mathbf{B}$, as shown in Scheme 4

SHE, Standard Hydrogen Electrode, $\mathrm{E}^{\mathrm{O}}=0 \mathrm{mV}$ when the fugacity of $\mathrm{H}_{2}=1$ and the activity of $\mathrm{H}^{+}=1$

Hm, histamine

ImH, imidazole

NMeIm, 1-methylimidazole

WEFT-NOESY, Water-Eliminated Fourier Transform-Nuclear Overhauser and Exchange SpectroscopY, a 2-dimensional homonuclear NMR experiment appropriate for samples having paramagnetic metal centers and hence broad ${ }^{1} \mathrm{H}$ signals

HMQC, Heteronuclear Multiple Quantum Coherence, a 2-dimensional heteronuclear NMR experiment

PDB, Protein Databank

\section{References}

1. Ribeiro JMC, Hazzard JMH, Nussenzveig R, Champagne D, Walker FA. Reversible Binding of Nitric Oxide by a Salivary Heme Protein from a Bloodsucking Insect. Science 1993;260:539-541. [PubMed: 8386393] 
2. Champagne DE, Nussenzveig RH, Ribeiro JMC. Purification, Partial Characterization, and Cloning of Nitric Oxide-carrying Heme proteins (Nitrophorins) from Salivary Glands of the Blood-sucking Insect Rhodnius prolixus. J. Biol. Chem 1995;270:8691-8695. [PubMed: 7721773]

3. Walker, FA.; Ribeiro, JMC.; Montfort, WR. Novel NO-Liberating Heme Proteins from the Saliva of Blood-Sucking Insects. In: Sigel, H.; Sigel, A., editors. Metal Ions in Biological Systems, Vol. 36, Interrelations between Free Radicals and Metal Ions in Life Processes. Marcel Dekker; New York: 1999. p. 619-661.

4. Walker, FA.; Montfort, WR. Nitric Oxide-Releasing Heme Proteins from the Saliva of the BloodSucking Insect Rhodnius prolixus. In: Mauk, AG.; Sykes, AG., editors. Advances in Inorganic Chemistry. 51. Academic Press; San Diego: 2001. p. 295-358.Ch. 5

5. Walker FA. Nitric Oxide Interaction with Insect Nitrophorins, and Thoughts on the Electron Configuration of the $\{\mathrm{FeNO}\}^{6}$ Complex. J. Inorg. Biochem 2005;99:216-236. [PubMed: 15598503]

6. Moreira MF, Coelho HS, Zingali RB, Oliveira PL, Masuda H. Changes in Salivary Nitrophorin Profile During the Life Cycle of the Blood-Sucking Bug Rhodnius prolixus. Insect Biochem. Mol. Biol 2003;33:23-28. [PubMed: 12459197]

7. Andersen JF, Gudderra N, Francischetti IMB, Valenzuela JG, Ribeiro JMC. Recognition of Anionic Phospholipid Membranes by an Antihemostatic Protein from a Blood-Feeding Insect. Biochemistry 2005;43:6987-6994. [PubMed: 15170336]

8. Valenzuela JG, Walker FA, Ribeiro JMC. A Salivary Nitrophorin (Nitric-Oxide-Carrying Hemoprotein) in the Bedbug Cimex lectularius. J. Exper. Biol 1995;198:1519-1526. [PubMed: 7658188]

9. Weichsel A, Maes EM, Andersen JF, Valenzuela JG, Shokhireva T. Kh. Walker FA, Montfort WR. Heme-Assisted Nitrosothiolation of a Proximal Thiol in a Nitric Oxide Transport Protein. Proc. Natl. Acad. Sci. U.S.A 2005;102:594-599. [PubMed: 15637157]

10. Ribeiro JMC, Nussenzveig RH. Nitric Oxide Synthase Activity from a Hemato-phagous Insect Salivary Gland. FEBS Lett 1993;330:165-168. [PubMed: 7689981]

11. Nussenzveig RH, Bentley DL, Ribeiro JMC. Ultrastructural Localization of the Salivary Diaphorase of Rhodnius prolixus. J. Exper. Biol 1995;198:1093-1098. [PubMed: 8627144]

12. Yuda M, Hirai M, Miura K, Matsumura H, Ando K, Chinzei Y. cDNA Cloning, Expression and Characterization of Nitric-Oxide Synthase from the Salivary Glands of the Blood-Sucking Insect Rhodnius prolixus. Eur. J. Biochem 1996;242:807-812. [PubMed: 9022713]

13. Ribeiro JMC, Walker FA. High Affinity Histamine-Binding and Antihistaminic Activity of the Salivary Nitric Oxide-Carrying Heme Protein (Nitrophorin) of Rhodnius prolixus. J. Exper. Med 1994;180:2251-2257. [PubMed: 7964498]

14. Ding XD, Weichsel A, Andersen JF, Shokhireva T. Kh. Balfour C, Pierik AJ, Averill BA, Montfort WR, Walker FA. Nitric Oxide Binding to the Ferri- and Ferroheme States of Nitrophorin 1, a Reversible NO-Binding Heme Protein from the Saliva of a Blood-Sucking Insect, Rhodnius prolixus. J. Am. Chem. Soc 1999;121:128-138.

15. Maes EM, Walker FA, Montfort WR, Czernuszewicz RS. A Resonance Raman Spectroscopic Study of Nitrophorin 1, a Nitric Oxide-Binding Heme Protein from the Saliva of the Blood-Sucking Insect Rhodnius prolixus, and its NO and Cyanide Adducts. J. Am. Chem. Soc 2001;123:11664-11672. [PubMed: 11716723]

16. Andersen JF, Ding XD, Balfour C, Champagne DE, Walker FA, Montfort WR. Kinetics and Equilibria in Ligand Binding by Nitrophorins 1-4: Evidence for Stabilization of a NO-Ferriheme Complex through a Ligand-Induced Conformational Trap. Biochemistry 2000;39:10118-10131. [PubMed: 10956000]

17. Shokhireva, T. Kh.; Berry, RE.; Uno, E.; Balfour, CA.; Zhang, H.; Walker, FA. Electrochemical and NMR Spectroscopic Studies of Single and Double Distal Pocket Mutants L122,132V of Nitrophorin 2: The Effect of Altering Distal Cavity Size on Stability, Structure and Dynamics of Axial Ligand Complexes. Proc. Natl. Acad. Sci. U.S.A 2003;100:3778-3783. [PubMed: 12642672]

18. Berry RE, Ding XD, Shokhireva T. Kh. Weichsel A, Montfort WR, Walker FA. Axial Ligand Complexes of Nitrophorins. Electrochemistry, Binding Constants and Structures of the Imidazole and 4-Iodopyrazole Complexes. J. Biol. Inorg. Chem 2004;9:135-144. [PubMed: 14673714] 
19. Shokhireva, T. Kh.; Shokhirev, NV.; Walker, FA. Assignment of Heme Resonances and Determination of the Electronic Structures of High- and Low-Spin Nitrophorin 2 by ${ }^{1} \mathrm{H}$ and ${ }^{13} \mathrm{C}$ NMR Spectroscopy: An Explanation of the Order of Heme Methyl Resonances in High-Spin Ferriheme Proteins. Biochemistry 2003;42:679-693. [PubMed: 12534280]

20. Shokhireva, T. Kh.; Smith, KM.; Berry, RE.; Shokhirev, NV.; Balfour, CA.; Zhang, H.; Walker, FA. Assignment of the Ferriheme Resonances for the High-Spin Form of Nitrophorins 1 and 4 by ${ }^{1} \mathrm{H}$ and ${ }^{13}$ C NMR Spectroscopy: Comparison to Structural Data Obtained from X-Ray Crystallography. Inorg. Chem 2007;46:170-178. [PubMed: 17198425]

21. Shokhireva, T. Kh.; Weichsel, A.; Smith, KM.; Berry, RE.; Shokhirev, NV.; Balfour, CA.; Zhang, H.; Montfort, WR.; Walker, FA. Assignment of the Ferriheme Resonances for Low-Spin Complexes of Nitrophorins 1 and 4 by ${ }^{1} \mathrm{H}$ and ${ }^{13} \mathrm{C}$ NMR Spectroscopy: Comparison to Structural Data Obtained from X-Ray Crystallography. Inorg. Chem 2007;46:2041-2056. [PubMed: 17290983]

22. Astashkin AV, Raitsimring AM, Walker FA. Two- and Four-Pulse ESEEM Studies of the Heme Binding Center of a Low-Spin Ferriheme Protein: The Importance of a Multi-Frequency Approach. Chem. Phys. Lett 1999;306:9-17.

23. Wegner P, Benda R, Schünemann V, Trautwein AX, Berry RE, Balfour CA, Wert D, Walker FA. How a Blood Sucking Insect Gets Its Meal: The Ferriheme Proteins Nitrophorin 2 and 4 Studied by Mössbauer Spectroscopy. Hyperfine Interact 2002;C5:253-256.

24. Andersen JF, Champagne DE, Weichsel A, Ribeiro JMC, Balfour CA, Dress V, Montfort WR. Nitric Oxide Binding and Crystallization of Recombinant Nitrophorin 1, a Nitric Oxide Transport Protein from the Blood-Sucking Bug Rhodnius prolixus. Biochemistry 1997;36:4423-4428. [PubMed: 9109649]

25. Weichsel A, Andersen JF, Champagne DE, Walker FA, Montfort WR. Crystal Structures of a Nitric Oxide Transport Protein from a Blood-Sucking Insect. Nature Struct. Biol 1998;5:304-309. [PubMed: 9546222]

26. Andersen JF, Montfort WR. The Crystal Structure of Nitrophorin 2, A Trifunctional Antihemostatic Protein from the Saliva of Rhodnius prolixus. J. Biol. Chem 2000;275:30496-30503. [PubMed: 10884386]

27. Andersen JF, Weichsel A, Balfour CA, Champagne DE, Montfort WR. The Crystal Structure of Nitrophorin 4 at $1.5 \AA$ Resolution: Transport of Nitric Oxide by a Lipocalin-Based Heme Protein. Structure 1998;6:1315-1327. [PubMed: 9782054]

28. Weichsel A, Andersen JF, Roberts SA, Montfort WR. Nitric Oxide Binding to Nitrophorin 4 Induces Complete Distal Pocket Burial. Nature Struct. Biol 2000;7:551-554. [PubMed: 10876239]

29. Roberts SA, Weichsel A, Qiu Y, Shelnutt JA, Walker FA, Montfort WR. Ligand-Induced Heme Ruffling and Bent NO Geometry in Ultra-High-Resolution Structures of Nitrophorin 4. Biochemistry 2001;40:11327-11337. [PubMed: 11560480]

30. Maes EM, Weichsel A, Andersen JF, Shepley D, Montfort WR. Role of Binding Site Loops in Controlling Nitric Oxide Release: Structure and Kinetics of Mutant Forms of Nitrophorin 4. Biochemistry 2004;43:6679-6690. [PubMed: 15157102]

31. Kondrashov DA, Roberts SA, Weichsel A, Montfort WR. Protein Functional Cycle Reviewed at Atomic Resolution: Conformational Change and Mobility in Nitrophorin 4 as a Function of $\mathrm{pH}$ and NO Binding. Biochemistry 2004;43:13637-13647. [PubMed: 15504026]

32. Maes EM, Roberts SA, Weichsel A, Montfort WR. Ultrahigh Resolution Structures of Nitrophorin 4: Heme Distortion in Ferrous CO and NO Complexes. Biochemistry 2005;44:12690-12699. [PubMed: 16171383]

33. Montfort WR, Weichsel A, Andersen JF. Nitrophorins and Related Antihemostatic Lipocalins from Rhodnius prolixus and other blood-sucking Arthropods. Biochim. Biophys. Acta 2000;1482:110118. [PubMed: 11058753]

34. Dickerson, RE.; Geis, I. Hemoglobin: Structure, Function, Evolution, and Pathology. Benjamin/ Cummings; Menlo Park: 1983.

35. Pesce A, Dewilde S, Nardini M, Moens L, Ascenzi P, Hankeln T, Burmester T, Bolognesi M. Human Brain Neuroglobin Structure Reveals a Distinct Mode of Controlling Oxygen Affinity. Structure 2003;11:1087-1095. [PubMed: 12962627] 
36. Vallone B, Nienhaus K, Brunori M, Nienhaus GU. The Structure of Murine Neuroglobin: Novel Pathways for Ligand Migration and Binding. Proteins: Struct. Func. Bioinf 2004;56:85-94.

37. Vallone B, Nienhaus K, Matthes A, Brunori M, Nienhaus GU. The Structure of Carbonmonoxy Neuroglobin Reveals a Heme-Sliding Mechanism for Control of Ligand Affinity. Proc. Natl. Acad. Sci. U.S.A 2004;101:17351-17356. [PubMed: 15548613]

38. de Sanctis D, Dewilde S, Pesce A, Moens L, Ascenzi P, Hankeln T, Burmester T, Bolognesi M. Crystal Structure of Cytoglobin: The Fourth Globin Type Discovered in Man Displays Heme Hexacoordination. J. Mol. Biol 2004;336:917-927. [PubMed: 15095869]

39. Stryer, L. Biochemistry. Ed. 4. W. H. Freeman; New York: 1995. p. 329

40. Lederer F, Glatigny A, Bethge PH, Bellamy HD, Matthew FS. Improvement of the $2.5 \AA$ Resolution Model of Cytochrome $b_{562}$ by Redetermining the Primary Structure and Using Molecular Graphics. J. Mol. Biol 1981;148:427-448. [PubMed: 7031264]

41. Arnesano F, Banci L, Bertini I, Faraone-Mennella J, Rosato A, Barker PD, Fersht AR. The Solution Structure of Oxidized Escherichia coli Cytochrome $b_{562}$. Biochemistry 1999;38:8657-8670. [PubMed: 10393541]

42. Finzel BC, Weber PC, Hardman KD, Salemme FR. Structure of Ferricytochrome $c^{\prime}$ from Rhodospirillum molischianum at 1.67 ̊ Resolution. J. Mol. Biol 1985;186:627-643. [PubMed: 3005592]

43. Xie Y, Lashuel HA, Miroy JG, Dikler S, Kelly JW. Recombinant Human Retinol-Binding Protein Refolding, Native Disulfide Formation, and Characterization. Protein Express. Purif 1998;14:31-37.

44. Yamaguchi H, Harada A. Supramolecular Formation of Antibodies with Viologen Dimers: Utilization for Amplification of Methyl Viologen Detection Signals in Surface Plasmon Resonance Sensor. Biomacromolecules 2002;3:1163-1169. [PubMed: 12425652]

45. Segel, IH. Enzyme Kinetics. Wiley-Interscience; New York: 1975. p. 73

46. Murataliev MB, Feyereisen R. Functional Interactions in Cytochrome P450 BM3. Evidence That NADP(H) Binding Controls Redox Potentials of the Flavin Cofactors. Biochemistry 2000;39:12699_ 12707. [PubMed: 11027150]

47. Zhang X, Cardosa L, Broderick M, Fein H, Davies IR. Novel Calibration Method for Nitric Oxide Microsensors by Stoichiometrical Generation of Nitric Oxide from SNAP. Electroanal 2000;12:425428.

48. Hoshino M, Maeda M, Konishi R, Seki H, Ford PC. Photochemistry of NO Adducts of Water-Soluble Iron(III) Porphyrin and Ferrihemoproteins Studied by Nanosecond Laser Photolysis. J. Am. Chem. Soc 1996;118:5702-5707.

49. Shokhirev, NV.; Walker, FA. Shift Patterns. 2001. http://www.shokhirev.com/nikolai/programs/prgsciedu.html

50. Shokhirev NV, Walker FA. The Effect of Axial Ligand Plane Orientation on the Contact and Pseudocontact Shifts of Low-Spin Ferriheme Proteins. J. Biol. Inorg. Chem 1998;3:581-594.

51. Walker FA, Emrick D, Rivera JE, Hanquet BJ, Buttlaire DH. The Effect of Heme Orientation on the Reduction Potential of Cytochrome $b_{5}$. J. Am. Chem. Soc 1988;110:6234-6240.

52. Ambrus A, Friedrich K, Somogyi A. Oligomerization of Nitrophorins. Anal. Biochem 2006;352:286295. [PubMed: 16574056] 
Immature sequences of nitrophorins

Native sequences of mature nitrophorins (underlined)

N-termini of nitrophorins expressed in E. coli

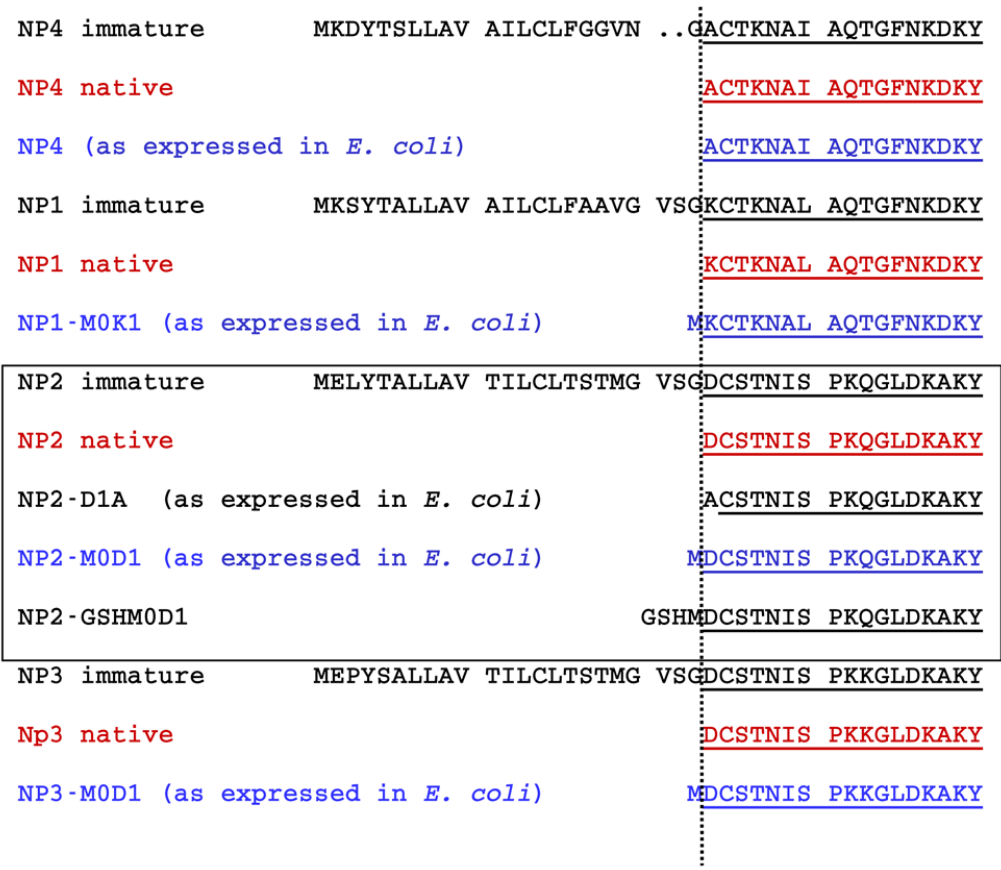

Scheme 1. 


$$
\mathrm{NP}^{\mathrm{III}}+\mathrm{Hm} \rightleftharpoons \mathrm{NP}^{\mathrm{III}} \mathbf{- H m}
$$

Scheme 2. 


$$
\mathrm{NP}^{\mathrm{III}}-\mathrm{Hm}+\mathrm{NO} \rightleftharpoons \mathrm{NP}_{k_{\text {on }}} \underset{k_{\text {off }}}{\longrightarrow}+\mathrm{Hm}+\mathrm{NO} \rightleftharpoons \mathrm{NP}^{\mathrm{III}}-\mathrm{NO}+\mathrm{Hm}
$$

Scheme 3. 


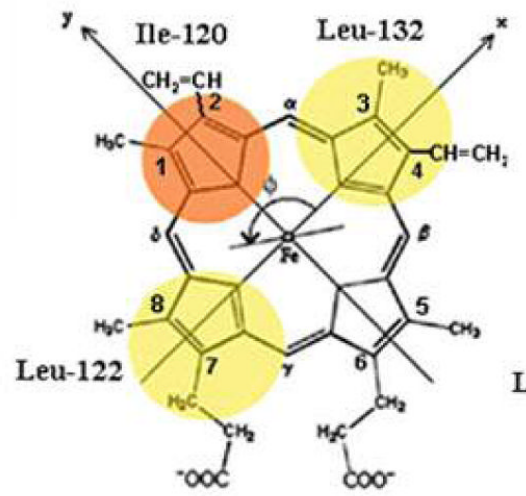

Ligand plane angle $=145^{\circ}$

A

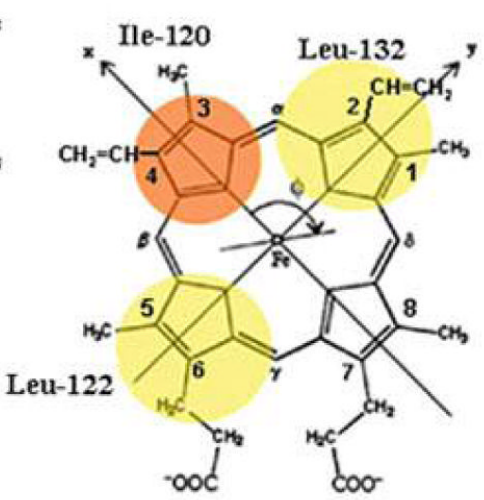

Ligand plane angle $=125^{\circ}$

B

Scheme 4. 


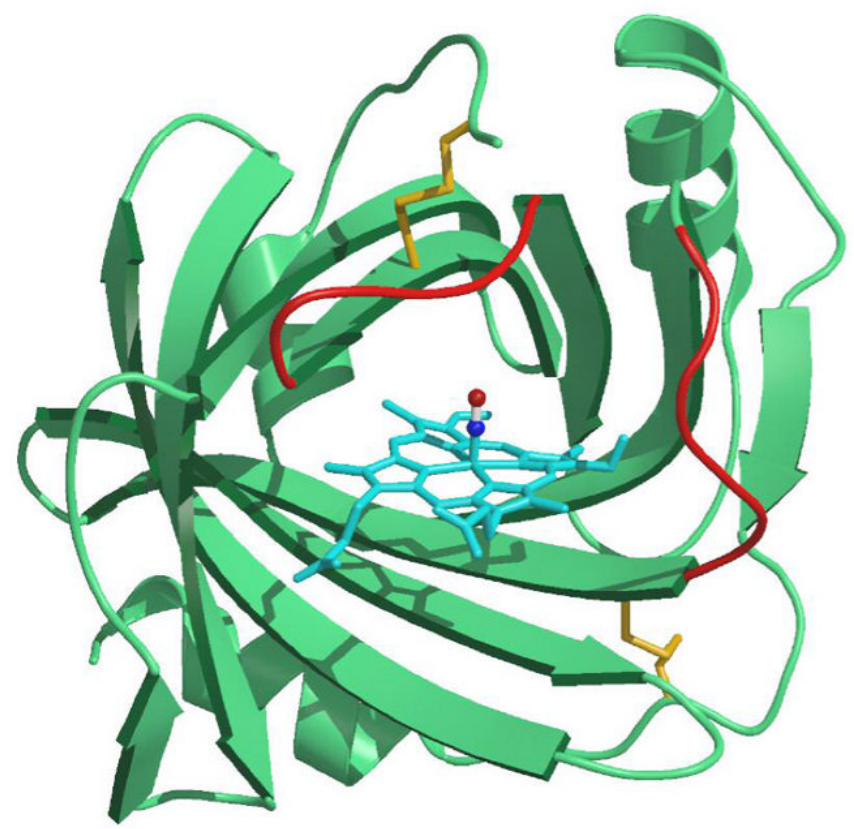

$a$
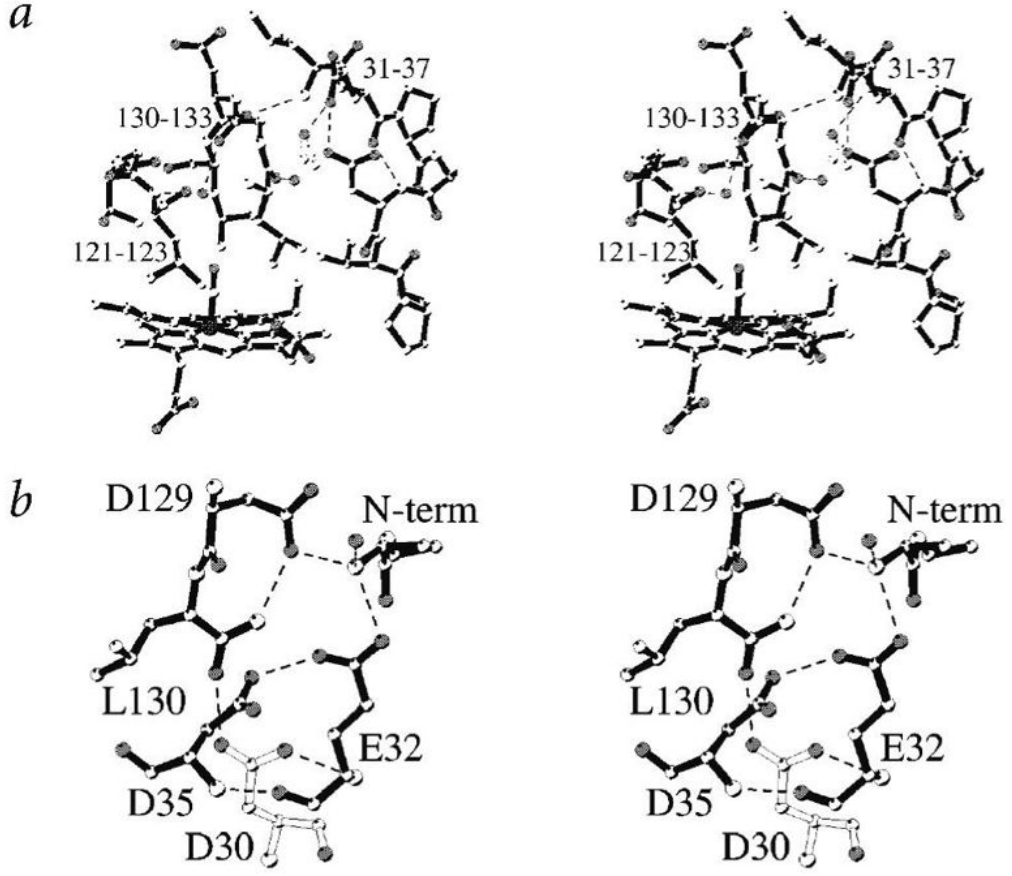

Figure 1.

Top: Ribbon drawing of the NP4-NO structure. The loops that move on NO binding (loop AB, residues 31-37 and loop G-H, residues 125-132) are colored red, the heme is cyan (stick representation), the disulfide bonds are yellow, and the linear NO representation in blue and red (ball and stick representation). The N-terminal A residue is seen at the top, just before the first disulfide bond. Bottom: Hydrogen bonding in the mobile loops of NP4. a) Stereo view of the distal pocket in NP4-NO. b) Stereo view of the N-terminus in NP4-NO. In a) and b), bonds are open for Asp 30 and filled for the other residues. Nitrogens are indicated by large open spheres, carbons by small open spheres, oxygens by shaded spheres, and hydrogen bonds by dashed lines. Reprinted from reference 25 with permission of Nature. 


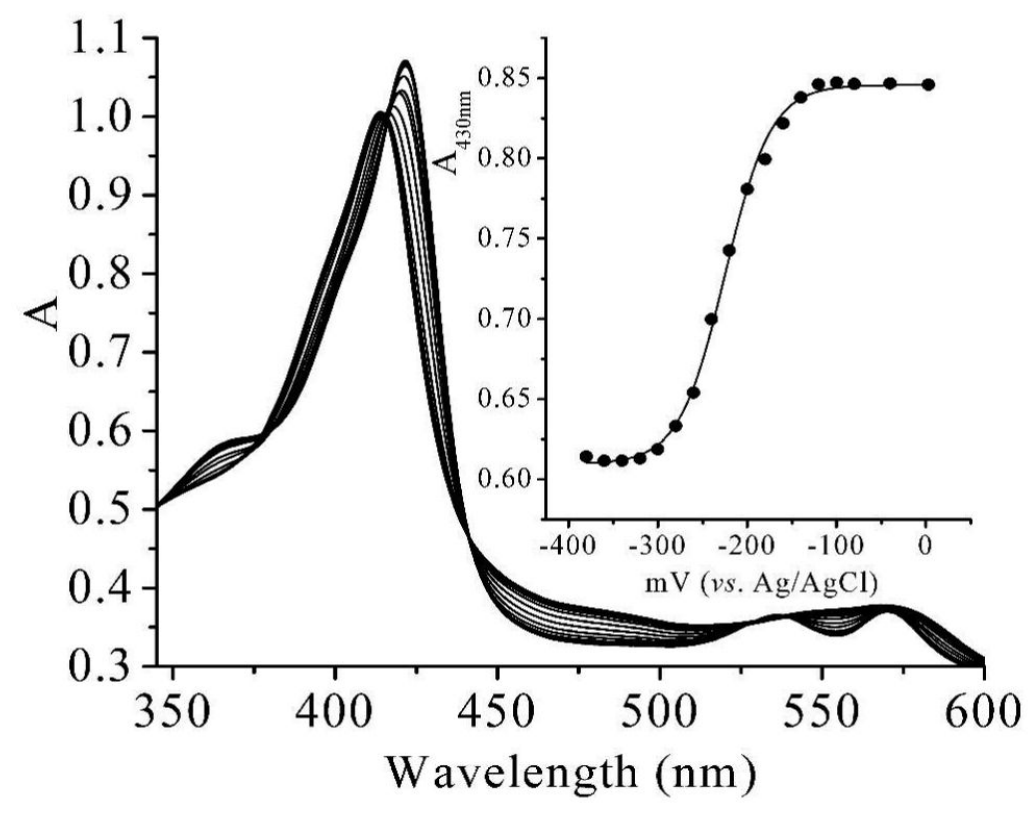

Figure 2.

Spectroelectrochemical titration of the NO complex of NP2-D1A at $\mathrm{pH} 7.5$ at $27^{\circ} \mathrm{C}$. The fit of the data to equation (1) is shown in the inset. 


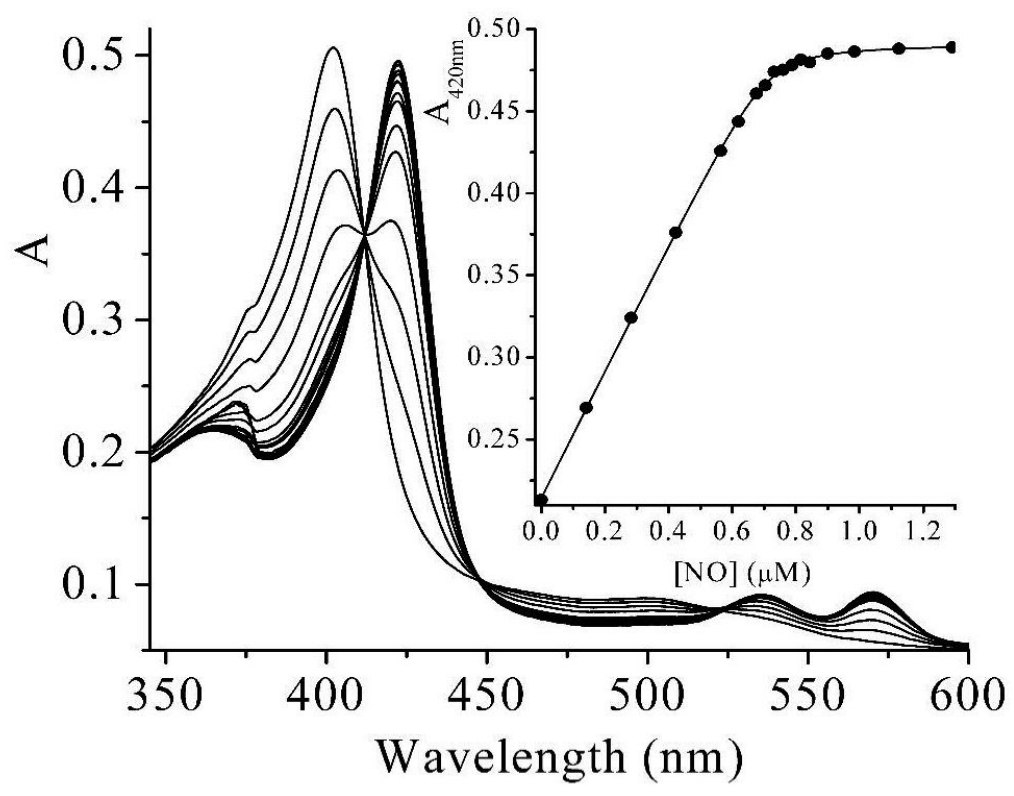

Figure 3.

Spectrophotometric titration of NP2-D1A with $\mathrm{NO}$ at $\mathrm{pH} 7.5,27^{\circ} \mathrm{C}$. The fit of the data to equation (3) is shown in the inset. 
A

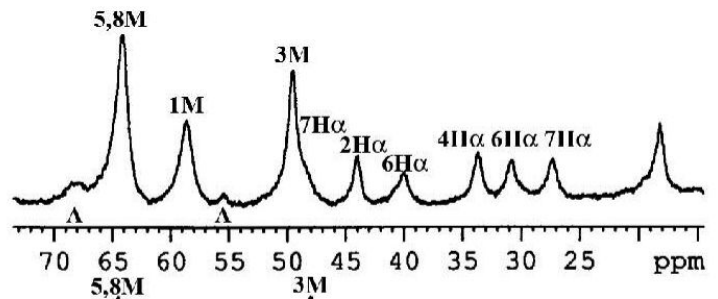

B
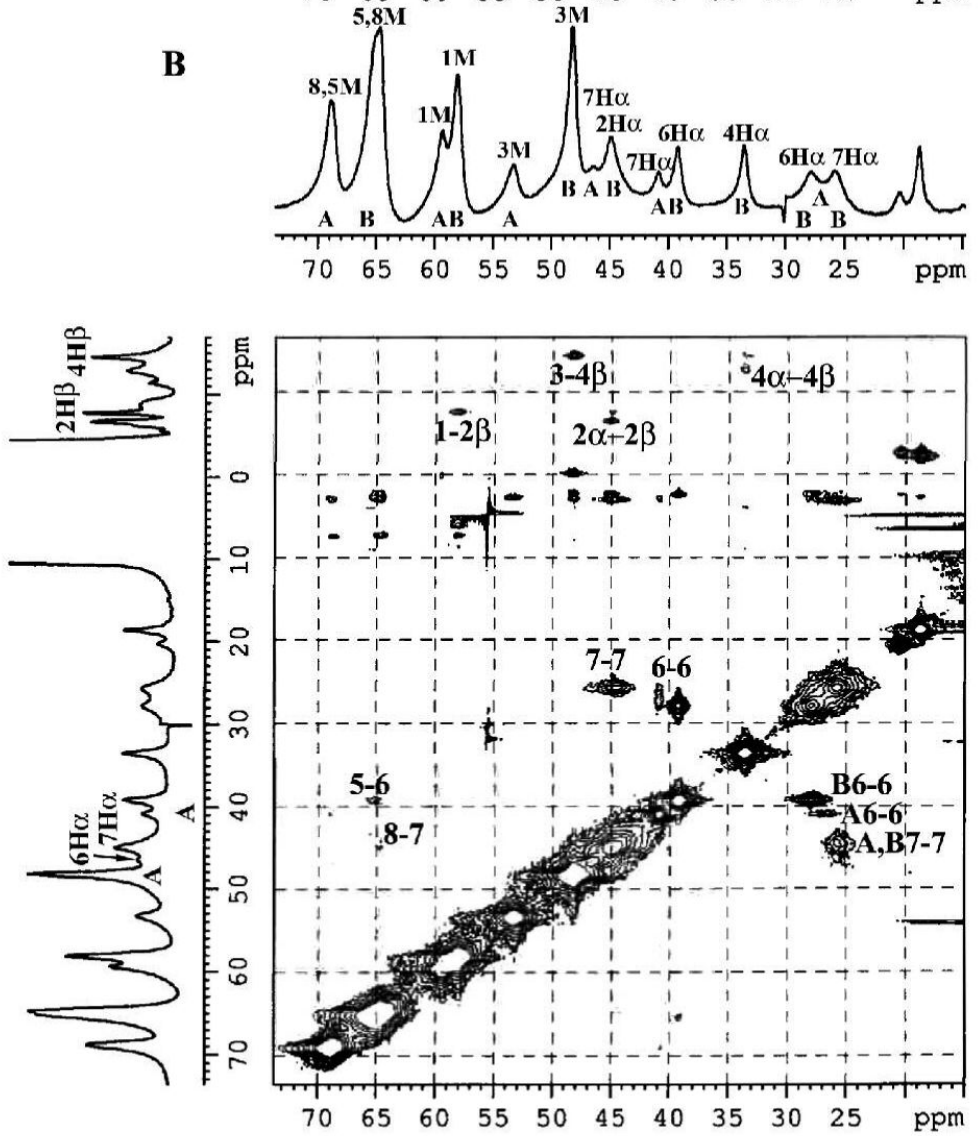

Figure 4.

A) NMR spectra of the high-spin form of NP2-M0D1 at pH 7.5 and $25^{\circ} \mathrm{C}$ as compared to B) that of NP2-D1A under the same conditions; C): WEFT-NOESY spectrum of the high-spin form of NP2-D1A, showing the NOEs for propionate and vinyl groups within each vinyl and to the heme methyl groups, and from methyls 5 and 8 to propionates 6 and 7, respectively, and from methyls 1 and 3 to vinyls- $\beta 2$ and 4 , respectively. Note that assignments to isomers $\mathbf{A}$ and $\mathbf{B}$ are marked below the peaks for NP2-D1A, and methyls, propionates and vinyls are labeled $\mathrm{M}, 6 \mathrm{H} \alpha, 7 \mathrm{H} \alpha, 2 \mathrm{H} \alpha$ and $4 \mathrm{H} \alpha$ for both isomers above the peaks. 

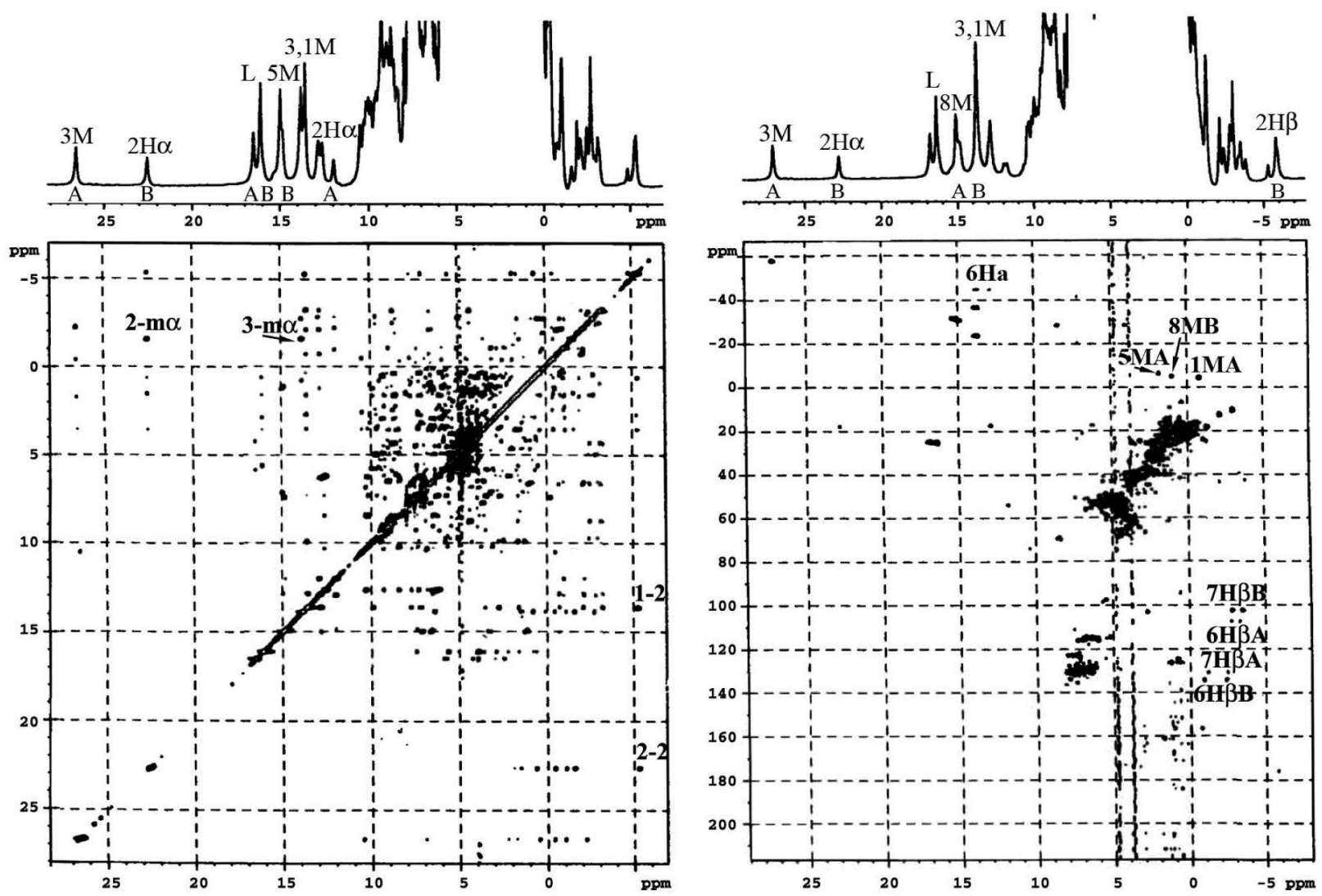

Figure 5.

WEFT-NOESY and HMQC spectra of the NMeIm complex of NP2-D1A at pH 7.0, at $32{ }^{\circ} \mathrm{C}$ and $25{ }^{\circ} \mathrm{C}$, respectively. Recorded at $500 \mathrm{MHz}$. Note that assignments to isomers $\mathbf{A}$ and $\mathbf{B}$ are marked below the peaks for NP2-D1A, and methyls, propionates and vinyls are labeled M, $6 \mathrm{H} \alpha, 7 \mathrm{H} \alpha, 2 \mathrm{H} \alpha$ and $4 \mathrm{H} \alpha$ for both isomers above the peaks in the $1 \mathrm{D}$ spectra. As can be seen, two methyl resonances of isomer $\mathbf{A}(3 \mathrm{M}, 8 \mathrm{M})$ and three methyl resonances of isomer $\mathbf{B}(1 \mathrm{M}$, $3 \mathrm{M}, 5 \mathrm{M})$ are resolved outside the diamagnetic envelope. In the WEFT-NOESY spectrum the cross peaks for the $\mathbf{B}$ isomer between $3 \mathrm{M}$ and meso- $\alpha$, between $2 \mathrm{H} \alpha$ and meso- $\alpha$, between $1 \mathrm{M}$ and $2 \mathrm{H} \alpha$ and between $2 \mathrm{H} \alpha$ and $2 \mathrm{H} \beta$ are marked. In the HMQC spectrum the proton chemical shifts of the methyl groups buried in the diamagnetic envelope, $1 \mathrm{M}$ and $5 \mathrm{M}$ of isomer $\mathbf{A}$ and $8 \mathrm{M}$ of isomer $\mathbf{B}$, the two $6 \mathrm{H} \alpha$ of isomer $\mathbf{A}$, as well as the two $6 \mathrm{H} \beta$ and $7 \mathrm{H} \beta$ for both $\mathbf{A}$ and $\mathbf{B}$ isomers are marked. 

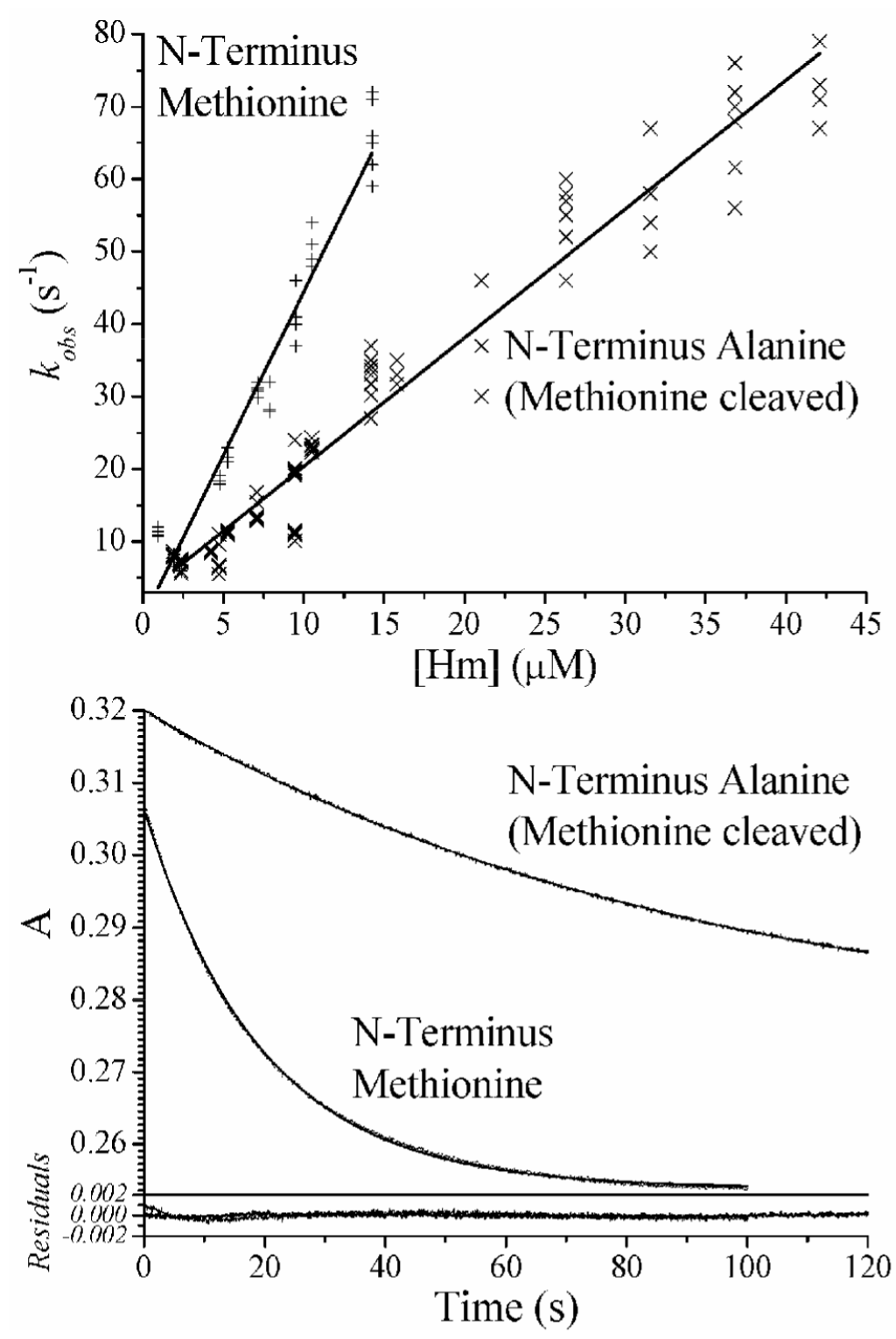

Figure 6.

Example of stopped-flow kinetics measurements on the histamine complex of NP2-D1A (x) and NP2-M0D1 (+) at pH 7.5. Top: Plot of $k_{o b s}$ values obtained from first order fits of a number of histamine binding reactions at various histamine concentrations, fit with a straight line to obtain $k_{\text {on }}$ from the slope. Bottom: Plot of absorbance change with time of a histamine displacement reaction, fit with a first order decay (with associated residuals shown) to obtain $k_{\text {off. }}$ 


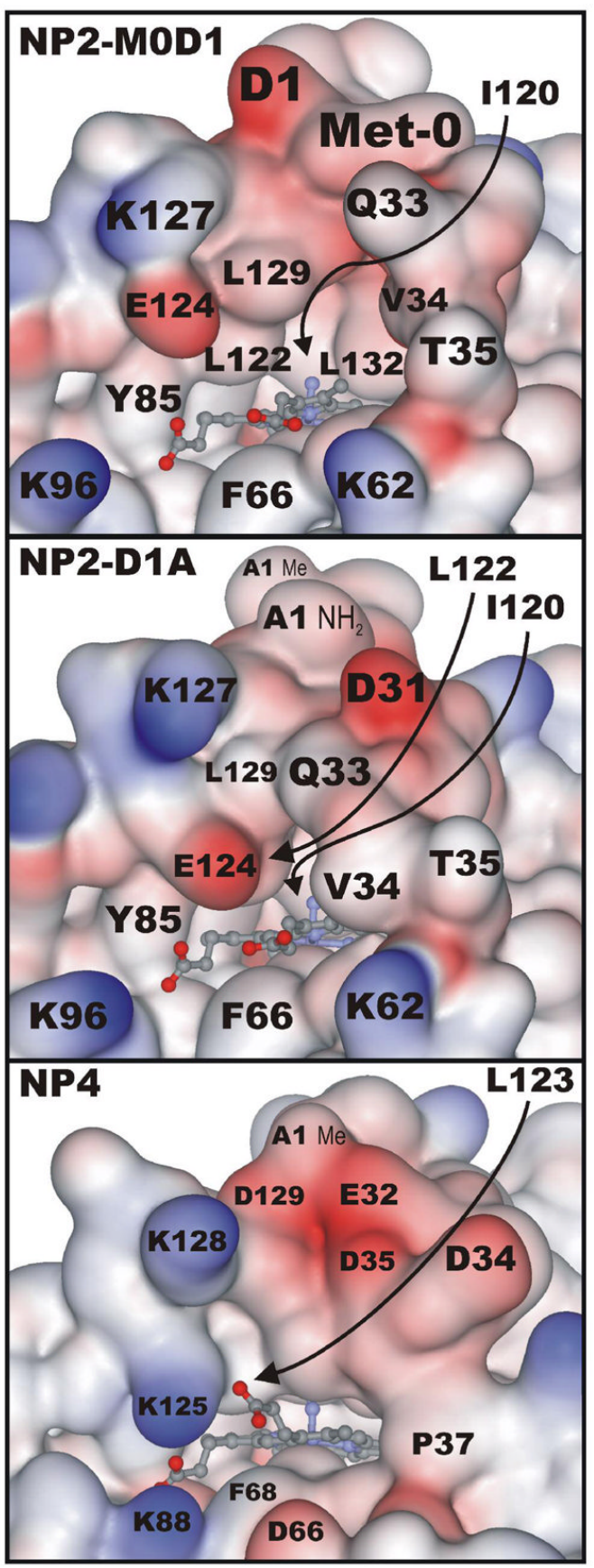

Figure 7.

Space filled surface representations of the mouth of the heme pocket; top: NP2-M0D1 (PDB 1EUO); middle: NP2-D1A (PDB 2EU7); bottom: NP4 (PDB 1KOI). For NP2-M0D1 the M0 side chain takes up quite a bit of space and prevents the A-B and G-H loops from closing at the mouth of the heme pocket. As evidence of this, the residues at the back of the distal pocket, I120 and L132, can be seen clearly in the NP2-M0D1 structure, while in NP2-D1A I120 is barely seen, and L132 cannot be seen. As is also evident, NP2-D1A has quite different side chains protruding at the front of the heme binding pocket than does NP2-M0D1. NP2-D1A and NP4 both have smaller and similar sized openings to the heme binding pocket. The 
difference in surface residues between this closed loop structure of NP2-D1A and NP4 is also evident (different protein sequences). 


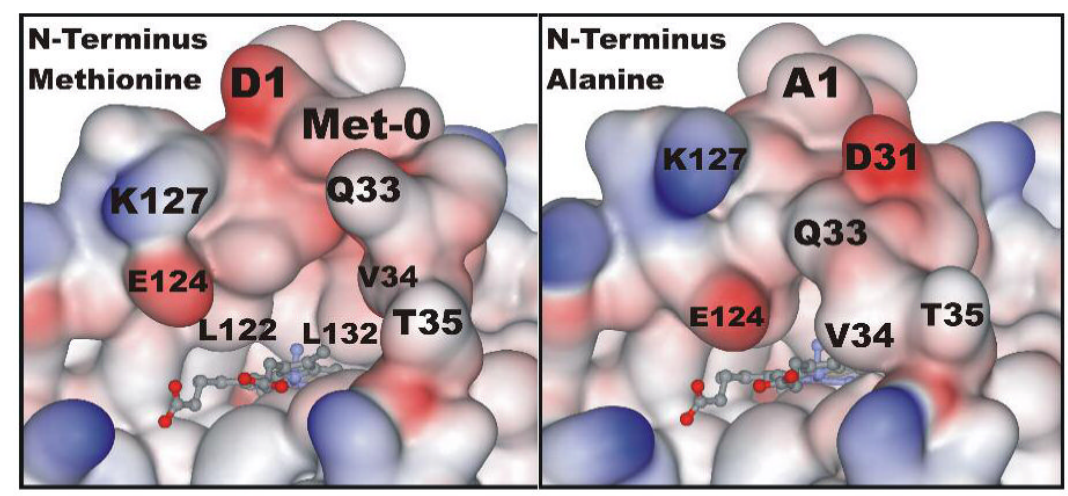

For Table of Contents Use Only. 


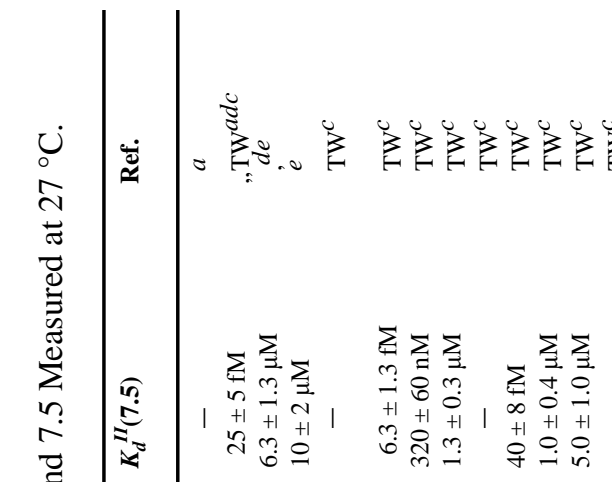

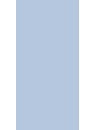

Z

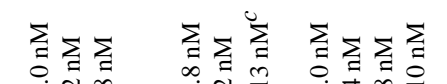

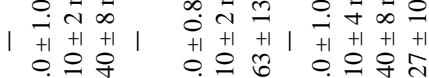

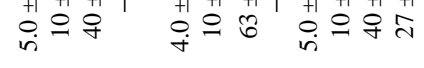

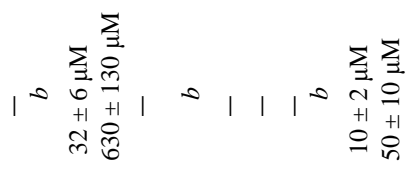

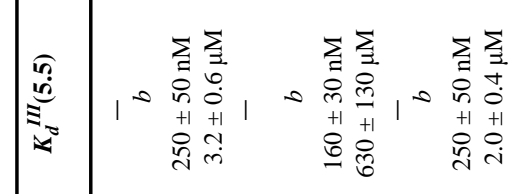

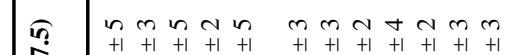

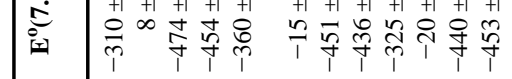

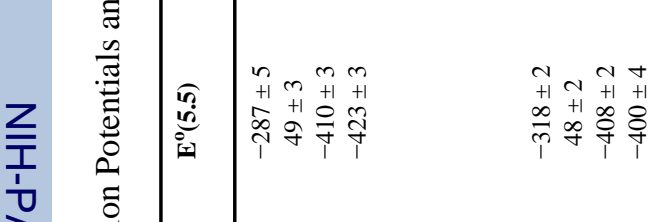

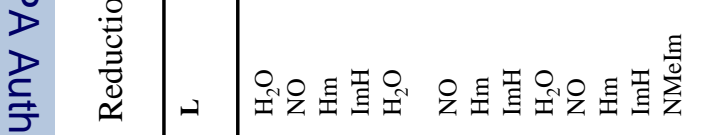

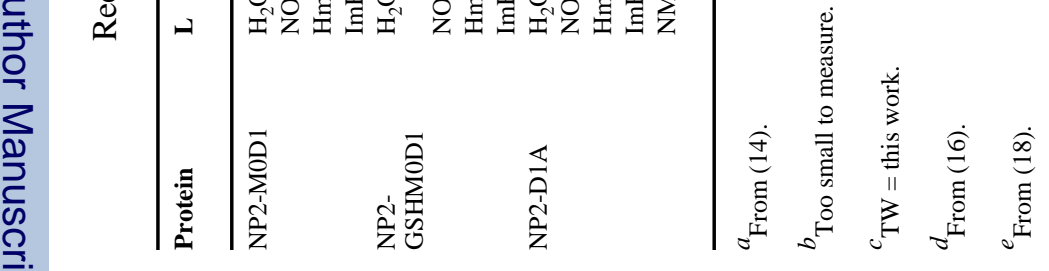


Table 2

Proton Chemical Shifts (ppm) of the High-spin Form of NP2-D1A as Compared to NP2-M0D1 at $25^{\circ} \mathrm{C}$, pH 7.0.

\begin{tabular}{|c|c|c|c|c|}
\hline & $\mathbf{A}$ & $\begin{array}{c}\text { NP2-D1A }(A: B=1: 2)^{a} \\
\text { Chemical shift, ppm } \\
\text { B }\end{array}$ & $\mathbf{A}$ & $\begin{array}{l}1(A: B=1: 8) \\
\text { l shift, ppm } \\
\text { B }\end{array}$ \\
\hline $1 \mathrm{Me}$ & 59.4 & 58.1 & $(55.5), b c$ & $58.6^{b}$ \\
\hline $3 \mathrm{Me}$ & 53.3 & 48.2 & $(\sim 53), b c$ & $49.5^{b}$ \\
\hline $5 \mathrm{Me}$ & 68.9 & 65.1 & $67.8^{a}$ & $64.1^{b}$ \\
\hline $8 \mathrm{Me}$ & 68.9 & 64.7 & $68.4^{a}$ & $64.1^{b}$ \\
\hline $2 \mathrm{H} \alpha$ & - & 46.5 & & $44.1^{c}$ \\
\hline $2 \mathrm{H} \beta$ & - & $-6.2,-7.3$ & & $-4.8,-7.9^{d}$ \\
\hline $4 \mathrm{H} \alpha$ & - & 33.6 & & $34.0^{d}$ \\
\hline $4 \mathrm{H} \beta$ & - & $-12.8,-14.1$ & & $-9.8,-13.2^{d}$ \\
\hline $6 \mathrm{H} \alpha$ & $46.5,25.9$ & $39.2,28.0$ & & $41.2,32.1^{\bar{d}}$ \\
\hline $6 \mathrm{H} \beta$ & - & $2.7,-{ }^{e}$ & & $2.7,-, d e$ \\
\hline $7 \mathrm{H} \alpha$ & $41.0,27.1$ & $44.9,25.9$ & & $50.6,28.4^{d}$ \\
\hline $7 \mathrm{H} \beta$ & 3.1 & $3.5,-e$ & & $3.1,-$ de \\
\hline Average Me & 62.6 & 59.0 & $\sim 61.2^{b}$ & $59.1^{b}$ \\
\hline Spread, $\Delta$ & 15.6 & 16.9 & $15.4^{b}$ & $14.6^{b}$ \\
\hline
\end{tabular}

${ }^{a}$ Ratio at the time the spectrum was recorded.

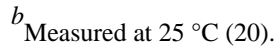

$c_{\text {Tentative assignments (20). }}$

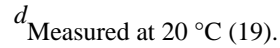

$e_{\text {Could not be assigned. }}$ 


\section{Table 3}

NP2-D1A-NMeIm Complex ${ }^{1} \mathrm{H}$ Heme Assignments in $\mathrm{D}_{2} \mathrm{O}$ at $\mathrm{pH}$ 7.0, as Compared to those of NP2-M0D1-NMeIm, at the Listed Temperatures.

\begin{tabular}{|c|c|c|c|}
\hline & $\mathbf{A}^{1} \mathbf{H}\left(3^{\circ}\right)$ & 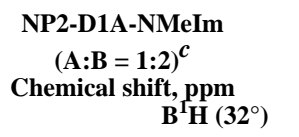 & $\begin{array}{l}\text { NP2-M0D1-NMeIm, } \\
(A b: B=1: 3)^{c} \\
\text { Chemical shift, ppm } \\
\text { B }^{1}\left(_{\left(25^{\circ}\right)}\right.\end{array}$ \\
\hline $\mathrm{N}-\mathrm{Me}$ & $16.5(16.8)^{a}$ & $16.0(16.4)^{a}$ & 16.1 \\
\hline $1 \mathrm{M}$ & -0.2 & 13.6 & 13.8 \\
\hline $3 \mathrm{M}$ & 26.6 & 13.8 & 13.4 \\
\hline $5 \mathrm{M}$ & 1.1 & 15.0 & 15.4 \\
\hline $8 \mathrm{M}$ & 14.8 & 1.65 & 1.0 \\
\hline $2 \mathrm{H} \alpha$ & 12.0 & 22.6 & 22.9 \\
\hline $2 \mathrm{H} \beta$ & $-5.4,-4.3$ & $-5.3,-5.3$ & $-5.6,-5.7$ \\
\hline $4 \mathrm{H} \alpha$ & 10.6 & 6.4 & 6.1 \\
\hline $4 \mathrm{H} \beta$ & $1.2,0.9^{a}$ & $1.2,0.6^{a}$ & $1.0,0.4$ \\
\hline $6 \mathrm{H} \alpha$ & $12.9,12.1$ & $13.0,13.5$ & $13.8,12.5$ \\
\hline $6 \mathrm{H} \beta$ & $-2.1,-0.9$ & $-2.0,-0.6$ & $-0.9,-2.4$ \\
\hline $7 \mathrm{H} \alpha$ & $9.7,5.1$ & $8.7,4.4$ & $8.0,4.1$ \\
\hline $7 \mathrm{H} \beta$ & $-2.4,-2.9$ & $-2.5,-3.1$ & $-3.0,-3.7$ \\
\hline meso- $\alpha$ & -2.1 & -1.5 & - \\
\hline meso- $\beta$ & - & 7.3 & 6.7 \\
\hline meso- $\gamma$ & -2.7 & -3.1 & -3.8 \\
\hline$m e s o-\delta$ & 7.5 & 9.9 & 9.5 \\
\hline
\end{tabular}

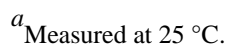

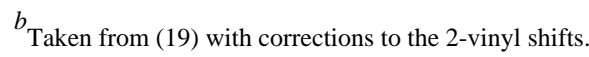

${ }^{c}$ Ratio at the time the spectrum was recorded, not at thermodynamic equilibrium. 


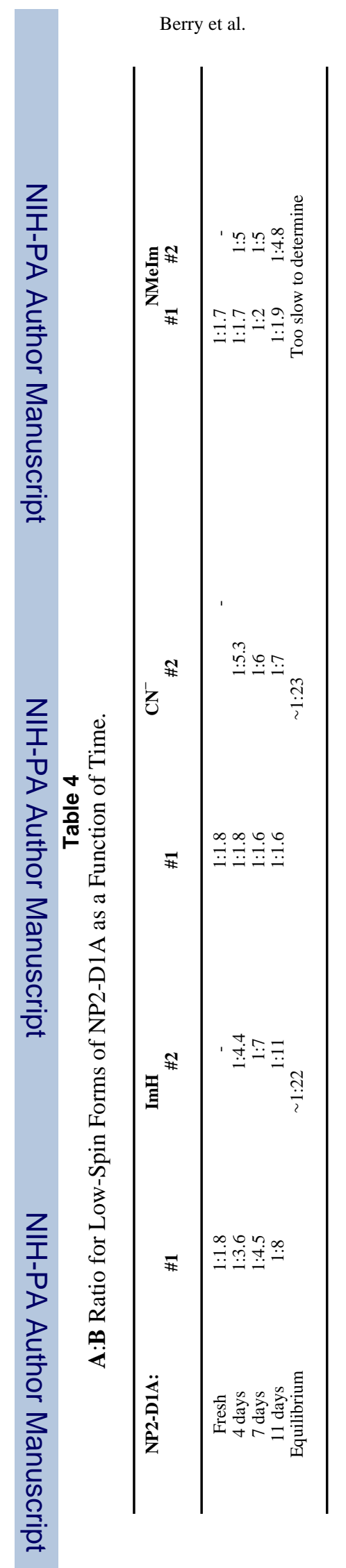

Page 34 
Table 5

Histamine Stopped-flow Kinetics Measurement Results.

\begin{tabular}{|c|c|c|}
\hline & NP2-M0D1 & NP2-D1A \\
\hline 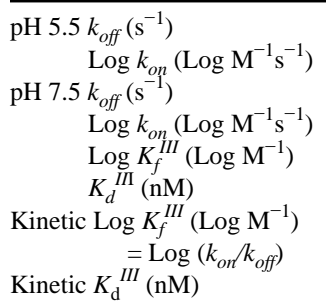 & $\begin{aligned} 0.163 & \pm 0.011 \\
5.8 & \pm 0.2^{a} \\
0.056 & \pm 0.003 \\
6.65 & \pm 0.01 \\
8.0 & \pm 0.1 \\
10 & \pm 2 \\
7.90 & \pm 0.03 b\end{aligned}$ & $\begin{aligned} 0.101 & \pm 0.011 \\
5.6 & \pm 0.1^{a} \\
0.011 & \pm 0.001 \\
6.25 & \pm 0.01 \\
8.0 & \pm 0.1 \\
10 & \pm 4 \\
8.19 & \pm 0.04^{b}\end{aligned}$ \\
\hline
\end{tabular}

All values were measured $\left(\right.$ at $23^{\circ} \mathrm{C}$ ) in this work, except

$a_{\text {the }} k_{O n}$ value at $\mathrm{pH} 5.5$ that was calculated from the $k_{\text {off }}$ value and $K_{d} I I I$ from Table 1.

${ }^{b}$ Kinetically determined $K_{f} I I I$ or $K_{d} I I I$ values were calculated from $k_{O f f} k_{O n}$ at $\mathrm{pH} 7.5$. 